\title{
Adult neurogenesis in the mammalian hippocampus: Why the dentate gyrus?
}

\author{
Liam J. Drew, ${ }^{1,2,5,6}$ Stefano Fusi, ${ }^{4}$ and René Hen ${ }^{1,2,3,6}$ \\ ${ }^{1}$ Division of Integrative Neuroscience, Research Foundation for Mental Hygiene, New York State Psychiatric Institute, New York 10032, \\ USA; ${ }^{2}$ Department of Psychiatry, Columbia University, New York 10032, USA; ${ }^{3}$ Department of Neuroscience, Columbia University, \\ New York 10032, USA; ${ }^{4}$ Center for Theoretical Neuroscience, Columbia University, New York 10032, USA
}

\begin{abstract}
In the adult mammalian brain, newly generated neurons are continuously incorporated into two networks: interneurons born in the subventricular zone migrate to the olfactory bulb, whereas the dentate gyrus (DG) of the hippocampus integrates locally born principal neurons. That the rest of the mammalian brain loses significant neurogenic capacity after the perinatal period suggests that unique aspects of the structure and function of DG and olfactory bulb circuits allow them to benefit from the adult generation of neurons. In this review, we consider the distinctive features of the DG that may account for it being able to profit from this singular form of neural plasticity. Approaches to the problem of neurogenesis are grouped as "bottom-up," where the phenotype of adult-born granule cells is contrasted to that of mature developmentally born granule cells, and "top-down," where the impact of altering the amount of neurogenesis on behavior is examined. We end by considering the primary implications of these two approaches and future directions.
\end{abstract}

Unequivocal data now detail the existence of adult hippocampal neurogenesis in mammals (Gross 2000), but it remains a contentious topic. Ample data, mainly drawn from studies of rodents, support the notion that adult-generated neurons make a significant contribution to hippocampal biology, but specific theories of adult-born granule cell (abGC) function remain at a nascent phase and many uncertainties remain in the field. Most current hypotheses focus on the idea that abGCs are for a period hyperplastic and/or hyperexcitable (see the section "Bottom-up: characterization of adult-born granule cells"). The most extreme proposes that mature developmentally born granule cells (matGCs) are "retired" and abGCs are the sole encoding units in the adult dentate gyrus (DG) (Alme et al. 2010).

In addition, aberrant adult neurogenesis has been argued, based largely on animal studies, to contribute to a significant and growing list of psychiatric and neurological conditions (see Box 1, below). Therefore understanding precisely what functions adult-born neurons perform is significant both academically and clinically.

Neurogenesis occurs during adulthood, at varying levels, in all vertebrate taxa (Barker et al. 2011). In nonmammals the process can be abundant; fish, amphibians, and reptiles have multiple neurogenic centers that retain proliferative capacity throughout life. In birds, adult-born neurons, although generated only in a periventricular niche, migrate widely throughout the brain (Nottebohm 2004; Lindsey and Tropepe 2006; Kaslin et al. 2008).

In stark contrast, the vast majority of the adult mammalian brain is devoid of significant neurogenic capacity. Therefore, one of the most conspicuous features of adult neurogenesis in mammals is that it is confined to two brain regions (Lledo et al. 2006): (1) the subventricular zone, where new interneurons are born that travel the rostral migratory stream to the olfactory

5Present address: Wolfson Institute of Biomedical Research,
University College London, London WC1E 6BT, UK
${ }^{6}$ Corresponding authors
E-mail liamdrew101@gmail.com
E-mail rh95@columbia.edu
Article is online at http://www.learnmem.org/cgi/doi/10.1101//m.026542.112. bulb, and (2) in the hippocampus, in the subgranular zone of the DG, where new principal cells, dentate GCs, are generated. This restricted distribution has been seen in every mammalian genus studied, including marsupials (Harman et al. 2003; Grabiec et al. 2009), indicative of this pattern having been established early in the phylogeny of mammals.

Despite this ubiquity, however, neurogenesis in the adult hippocampus varies widely across species, with differences apparent in the rate of proliferation, survival, and neuronal maturation (for example, Cavegn et al. 2013). The process appears absent in certain bat species (Amrein et al. 2007), whereas especially high levels are found in rodents, especially rats (Amrein et al. 2011). Where on this spectrum the rate of adult hippocampal neurogenesis in primates, and especially humans, falls is an essential issue; most data suggest it is toward the low end, but a recent study found that a steady rate of hippocampal neurogenesis $(\sim 0.004 \%$ of GCs daily, akin to that in middle-aged rodents) is maintained throughout human life and, interestingly, that a substantially greater fraction of human GCs is subject to turnover (Spalding et al. 2013). Determining the functional significance of neurogenesis in the adult human hippocampus is, arguably, the most outstanding task in this field (see Box 1).

These observations, the intricate regulation of its biology, such as its regulation by experience and environment (see the section "Adult hippocampal neurogenesis and its regulation"), and accumulating evidence that it makes unique contributions to mammalian cognition (see "Top-down: behavioral effects of altering neurogenesis") are consistent with adult hippocampal neurogenesis being a phenotype that selective pressures have both preserved (for $>200$ million yr) and acted upon throughout mammalian evolution. They also indicate that detailed comparative

\footnotetext{
C 2013 Drew et al. This article is distributed exclusively by Cold Spring Harbor Laboratory Press for the first 12 months after the full-issue publication date (see http://learnmem.cshlp.org/site/misc/terms.xhtml). After 12 months, it is available under a Creative Commons License (AttributionNonCommercial 3.0 Unported), as described at http://creativecommons. org/licenses/by-nc/3.0/.
} 
BOX 1. Adult hippocampal neurogenesis in humans

The single most controversial issue in the field of adult neurogenesis is the extent to which it occurs in humans and how substantially abGCs impact human cognitive processing (Rakic 1985). In addition to the question of how abGCs might contribute to human cognitive abilities, the utility of targeting adult neurogenesis for the treatment of psychiatric and neurological diseases is also at stake. Animal model studies have suggested that aberrant adult neurogenesis might contribute to the pathophysiology of depression and stress responses (Schloesser et al. 2009; Snyder et al. 2011; Dranovsky and Leonardo 2012), the response to antidepressants (Santarelli et al. 2003), post-traumatic stress disorder and anxiety (Kheirbek et al. 2012b), epilepsy (Parent et al. 1997; Scharfman et al. 2000; Pun et al. 2012), schizophrenia (Kvajo et al. 2008, 2011; Christian et al. 2010), Alzheimer's disease (Galvan and Bredesen 2007; Mu and Gage 2011), drug addiction (Mandyam and Koob 2012), and Fragile $X$ syndrome (Guo et al. 2011). Although it seems unlikely that adult neurogenesis will critically contribute to all of these disorders, there are certainly grounds to anticipate that ways of successfully manipulating adult neurogenesis will find clinically beneficial uses.

Observations in nonhuman primate studies showing relatively low rates of adult neurogenesis in the DG (Rakic 1985; Kornack and Rakic 1999) and a protracted course of maturation of these cells (Kohler et al. 2011) cast doubt on the likelihood of significant hippocampal neurogenesis in mature people. However, Eriksson et al. (1998) detected newborn neurons in the DG of terminal cancer patients given single BrdU injections, indicating that adult hippocampal neurogenesis does, indeed, occur in humans. Postmortem studies employing immunohistochemical analysis of markers of neural progenitors and/or young neurons are consistent with this and, moreover, such studies indicate that antidepressants increase the proliferation of subgranular zone neural progenitor cells in humans (Boldrini et al. 2009, 2012). Knoth et al. (2010) further analyzed immunoreactivity for young neuron markers in postmortem human hippocampi and found evidence for pronounced neurogenesis in adults but that rates reduced substantially in advanced age.

Conversely, a recent analysis of cellular levels of radiocarbon, absorbed due to atmospheric fallout from nuclear testing from 1945 to 1963 , to birth-date neurons led Spalding et al. (2013) to conclude that adult neurogenesis is maintained in human adulthood, throughout old age even, and at rates comparable to those seen in middle-aged rodents. Determining the functional impact of these neurons in primates remains, however, an outstanding challenge.

Attempts to image neural stem cells in vivo using MRI (Manganas et al. 2007), which would have clear clinical utility, remain subject to confirmation (Friedman 2008; Hoch et al. 2008; Jansen et al. 2008).

studies are likely to be important in informing us of its function (Barker et al. 2011; Kempermann 2012).

This review seeks to place the process of adult hippocampal neurogenesis in the context of the structure and function of the DG. That the addition of new neurons was lost from nearly all brain regions early in mammalian evolution strongly implies that unique features of the DG and the olfactory bulb networks allow these regions to benefit from (or, at the very least, accommodate) the addition of new units.

Over the last two decades, the study of adult hippocampal neurogenesis has mushroomed, almost eclipsing investigation of overall DG function. However, understanding the unique circuitry of the DG, how it locally processes information, and what specific functions it contributes to hippocampal biology are all necessary to provide a framework for understanding the function of abGCs. Below, we consider adult neurogenesis in this context. We begin with overviews of DG structure and function ("The mammalian dentate gyrus") and the process of adult neurogenesis ("Adult hippocampal neurogenesis and its regulation"). Then we discuss investigations aimed at accounting for the function of ongoing neurogenesis; studies are categorized as taking either a bottom-up approach, i.e., characterizing the cellular properties of abGCs ("Bottom-up: characterization of adult-born granule cells"), or as top-down, i.e., determining the behavioral effects of altering neurogenesis ("Adult hippocampal neurogenesis and its regulation"). We end with a general discussion ("Conclusions: toward a circuit-based understanding of adult hippocampal neurogenesis") that highlights some of the current theories of adult hippocampal neurogenesis, what issues and discrepancies remain outstanding, and what possible future research directions might prove fruitful in helping to determine the operational advantage for the DG circuit, and thus the animal, of generating new neurons in adulthood.

\section{The mammalian dentate gyrus}

Determining how the hippocampus' well-defined circuitry underlies its essential contribution to episodic memory formation and its less resolved role in regulating affect and goal-oriented behavior remains an ongoing pursuit.

At the core of the hippocampus is the recurrently connected network of CA3 pyramidal neurons, which is thought to form an autoassociative network essential for storing representations of sensory experience (Marr 1971; Rolls and Treves 1998). The majority of excitatory synapses on each CA3 pyramidal neuron arise from collateral fibers of other CA3 pyramidal cells. Afferent information arrives primarily from layer II neurons of the entorhinal cortex (EC) that project both directly to CA3, terminating on pyramidal neurons' distal apical dendrites, and indirectly via dentate GCs, whose mossy fiber (MF) axons synapse on the proximal dendrites (see Spruston and McBain 2007).

The DG (Fig. 1) consists of the densely packed granule cell layer (GCL), the overlying molecular layer, where the axons of layer II EC neurons terminate, and the underlying polymorphic cell layer of the hilus, through which the MF axons travel to CA3 (Amaral et al. 2007). The GC is the sole principal cell type of the DG, as it alone projects outside of this region and as GCs project only to CA3, all theories of DG function must ultimately describe how GC activity affects CA3 information processing.

The majority of neurons in the GCL are mature developmentally generated GCs, but a sizeable subpopulation (up to $10 \%$ in mice [Imayoshi et al. 2008]) are GCs born in adulthood and, additionally, at the GCL-molecular layer border there is a unique subtype of GC termed the semilunar GC (Williams et al. 2007). Semilunar GCs have firing properties distinct from those of regular GCs, showing sustained activity in response to brief inputs, and strongly activate hilar neurons (Larimer and Strowbridge 2010).

The diversity of cell types in the hilus and of the GABAergic interneurons (INs) of the molecular layer (Houser 2007) demonstrate the complexity of intrinsic DG circuitry and suggest extensive information processing therein. For example, perisomatic targeting basket cells residing near, or within, the GCL receive excitatory drive from both EC afferents (Zipp et al. 1989) and GCs (Geiger et al. 1997). Therefore, these basket cells mediate both (what would classically be defined as) feedforward and feedback inhibition (Sambandan et al. 2010). Other INs mediate dendritic 


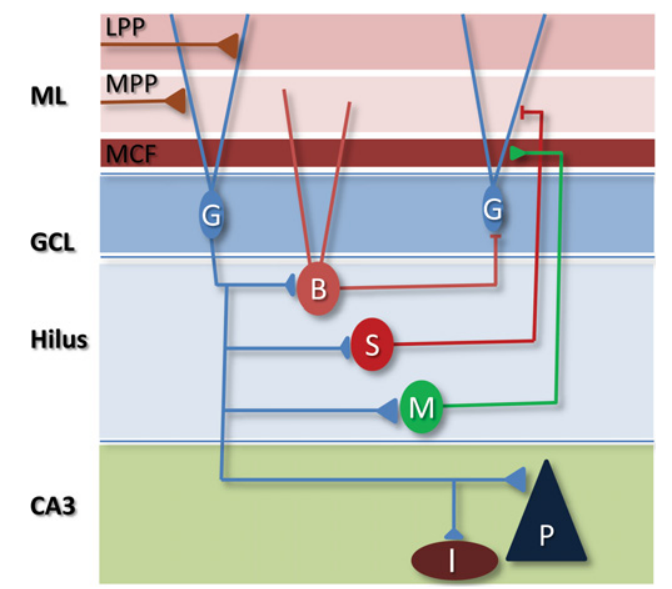

Figure 1. Local circuitry of the DG. The dendrites of GCs (G) receive three primary bands of excitatory drive in the molecular layer $(\mathrm{ML})$ from proximal to distal-mossy cell fibers (MCF), medial entorhinal cortical inputs via the medial perforant path (MPP), and lateral entorhinal cortex via the lateral perforant path (LPP). GCs also receive synaptic input from the hypothalamus, perirhinal cortex, and cholinergic neurons of the septum, and the region contains serotoninergic, noradrenergic, and dopaminergic projections. GCs innervate a number of cel types in the hilus, including glutamatergic mossy cells (M) and various GABAergic interneuron subtypes including basket cells (B), that express parvalbumin or cholecystokinin, and dendritic targeting neurons, many of which express somatostatin (S). Most of these cells project "back" to the $\mathrm{GCL}$, as well as there being connections between hilar neurons. In $C A 3$, each GC innervates a small number of pyramidal neurons $(P)$ and numerous GABAergic interneurons $(I)$ in the stratum lucidum region.

targeted feedback inhibition and molecular layer INs modulate EC afferent release in a feedforward fashion (see Buhl and Whittington 2007; Houser 2007). Finally, glutamatergic mossy cells of the hilus are excited primarily by GCs, although those with dendrites in the molecular layer are innervated by EC afferents also (Scharfman 1991). Mossy cells form a recurrent excitatory loop through the axons they project back to the proximal dendrites of GCs (Scharfman 1995). Mossy cells also innervate local inhibitory INs that target GCs (Scharfman 1995; Jinde et al. 2012). Although significant progress has been made in unraveling the dynamics of hippocampal microcircuits in CA1 (e.g., Pouille and Scanziani 2004; Lovett-Barron et al. 2012), similarly detailed analyses of DG microcircuits are only beginning (Ewell and Jones 2010).

The functions of the DG remain the subject of active debate (Treves et al. 2008). Much attention has focused on the DG's potential role as a pattern separator ( $\mathrm{O}^{\prime}$ Reilly and McClelland 1994; Kesner 2007; Schmidt et al. 2012; Hunsaker and Kesner 2013). Current models of memory formation focus on sensory experiences being encoded into a pattern of synaptic weights among a cluster of interconnected CA3 pyramidal neurons, and, for memory recall, the ability of such a cell ensemble to be reactivated by input constituting only a part of the original experience, a process termed pattern completion (Marr 1971; O'Reilly and McClelland 1994; Rolls and Treves 1998).

A potential problem with such a process would be if the activated CA3 ensemble during encoding was selected directly by the sensory content of the experience, as then similar inputs would be stored by largely overlapping ensembles (i.e., a visit to a red, circular, and rose-scented room, say, would be encoded by many of the same cells as a subsequent trip to a red, circular room that smelt of menthol). In such a situation, similar inputs (cuing recall) that should generate different responses may, instead, evoke the same memory when pattern completion is engaged (i.e., if a dog bit you in the florally scented room, menthol might erroneously generate a fearful recollection of a canine attack). Hence, pattern separation is required so that similar inputs are made more distinct for storage in distinct subpopulations of CA3 pyramidal neurons as discrete memory items (O'Reilly and McClelland 1994; Rolls and Treves 1998). There is now support from behavioral studies that the DG functions in pattern separation (Kesner 2007, 2013) and this will be discussed alongside studies linking adult neurogenesis to pattern separation in the section "abGCs and pattern separation". Whether anatomically specific DG-CA3 interactions are required to mediate particular computations, i.e., whether the DG-CA3 network is functionally homogenous, remains an outstanding question. Employing specific lesions of hippocampal subfields, Hunsaker et al. (2008) found that the DG was essential for animals to respond to small changes in the environment, and also observed that area CA3c (the region closest to the DG) was required for this discrimination, whereas CA3a and $b$ were not.

In theoretical studies proposing a critical role for the DG in pattern separation, two aspects of its physiology and connectivity have been emphasized; one, the large number, relative to CA3 and EC, of principal cells it contains, and, two, its sparse activity (O'Reilly and McClelland 1994). The rat DG contains around a million GCs-meaning that it outnumbers its 300,000 target CA3 pyramidal neurons by about 3:1 and its upstream 200,000 EC neurons by 5:1 (Amaral et al. 1990). The remapping of the activity of EC neurons onto the much larger, sparsely active GC population is what Marr defined as "expansion recoding" and it is hypothesized to be a central step in separating EC activity patterns, as small changes in EC activity would be thought to change significantly the activated cohort of GCs. Indeed, the influential theoretical study of O'Reilly and McClelland (1994) indicated that the distance between neural representations in the DG is systematically larger than in the EC when DG representations are sparse. This form of decorrelation improves separability, however it also disrupts the ability of the CA3 neurons to perform pattern completion.

One of the limitations of these models is that they mostly focus on the distances between neural representations, assuming that these are central to any readout mechanism that resides in CA3 or downstream areas. However, although it is certainly true that such distances are important, they are not sufficient to determine the performance of the readout (see, for example, Barak et al. 2013). Moreover, because it is not especially difficult to separate two patterns of activity, even when they have large overlaps, in these models the performance improvement due to the DG is relatively small. Hence, although there is good empirical support for the DG functioning in discriminative learning of two similar contexts, these considerations suggest that we may need to consider problems that are more complex than simple pattern separation if we want to understand the role of the DG, why it evolved, and what the full computational advantages are of its sparseness.

Sparse DG activity was originally noted by O'Keefe and colleagues during their seminal work defining the in vivo firing properties of hippocampal neurons (O'Keefe and Nadel 1978) and very sparse activity is now viewed as a distinctive feature of the DG (Chawla et al. 2005; Neunuebel and Knierim 2012). Over the subsequent three-and-half decades surprisingly few papers have been published on the natural firing patterns of DG GCs, indicative of the technical difficulties of recording in this area. But those few studies have confirmed sparse activity and low basal firing rates (see Box 2). Additionally, multiple investigations have used the induction of immediate early genes (IEG) as a proxy for GC activation by recent experience (Guzowski et al. 2005). These studies support the idea that over the period of the experimentally 
BOX 2. In vivo recordings of GC firing

To understand how spatial and mnemonic information is processed by the DG it will be necessary to know how both matGCs and abGCs fire in the awake behaving animal. Compared to studies of the firing properties of CA1 and CA 3 neurons in vivo, few investigations of the DG exist. This is, in part, due to the technical demands of working in this area (e.g., small densely packed cells that are difficult to isolate, sparse firing).

With respect to pattern separation, the most influential study is that of Leutgeb et al. (2007) who recorded from the DG and CA3 in rats as the animals were exposed to incrementally morphed environments. As the environment was progressively changed, the firing patterns of GCs and pyramidal neurons gradually changed. With small alterations of the animal's surroundings GCs showed more pronounced rate remapping (i.e., changes in firing rate and spatial selectivity of firing) than CA3 neurons, consistent with a pattern separating function. Interestingly, GCs only rate-remapped whereas across larger environmental differences CA3 displayed global remapping (i.e., different cells came to represent the space).

Although rate-remapping was greater in the DG, it was puzzling that GCs displayed multiple place fields (an observation made also by Jung and McNaughton [1993]) for this would mean that downstream cells would not be able to disambiguate two distinct locations represented in the firing of that single GC. Moreover, that CA3 pyramidal neurons had only single place fields was inconsistent with a GC's purported ability to strongly drive activity in CA3 pyramidal neurons (Henze et al. 2002). And equally surprising for a pattern separator, when the animal was transferred to a second environment (sometimes in a different room) the same DG neurons were active in both (Alme et al. 2010). This constancy of active cells would suggest that, rather than recruitment of different cell cohorts in different contexts as originally hypothesized (see "The mammalian dentate gyrus"), DG pattern separation operates on changes in firing behavior across the entire population.

However, Neunuebel and Knierim (2012) have recently suggested that previous studies may not have been recording from matGCs. By systematically tracking the position of their recording electrodes through the GCL, these authors report that matGCs in the outer GCL have single, small, discrete place fields, i.e., each matGC represents a very specific aspect of a given environment. Cells with multiple place fields were only observed at the GCL-hilus border, which led to the suggestion that previous reports (e.g., Jung and McNaughton 1993; Leutgeb et al. 2007) may have reported the spiking of either mossy cells or abGCs. Neunuebel and Knierim (2012) only reported GC activity in a single environment. Clarification of these issues and further characterization of GC activity in vivo, hence, awaits further investigation.

defined experience only $2 \%-5 \%$ of total GCs generate sufficient activity to induce such an activity marker (Chawla et al. 2005; Ramírez-Amaya et al. 2005). Understanding the means by which this small subset of active cells is selected is a fundamental question in DG physiology (Lisman 2011) and the role of abGCs in modulating this process and, to what degree they contribute to the active cohort, are central issues in the investigation of adult neurogenesis.

The DG is also theorized to be involved in other important aspects of memory encoding, including conjunctive encoding, context-object recognition, and pattern separation in modalities other than contextual encoding (see Xavier and Costa 2009; Kesner 2013). For example, it is of note that the two bands of entorhinal cortical input carry both spatial (medial EC) and nonspatial (lateral EC) input (Hargreaves et al. 2005) and the ventral DG specifically appears to mediate discriminative memorization of closely related odors (Kesner et al. 2011). In addition, the functions of the DG in memory consolidation and recall are less wellstudied (see the section "Contextual and spatial memory"). Moreover, how the DG contributes to affective regulation remains to be determined (see the section "abGCs and affect").

\section{Adult hippocampal neurogenesis and its regulation}

Adult-born neurons arise from neural stem cells that reside in the subgranular zone. The generation of functional, integrated neurons from these cells is a complex multistage process beyond the scope of this article (for reviews, see Zhao et al. 2010a; Ming and Song 2011). Briefly, pluripotent radial glia-like stem cells divide to generate neural progenitor cells (as well as astrocytes and further stem cells) which then undergo mitosis to generate new neurons (Bonaguidi et al. 2011; Dranovsky et al. 2011). Then, over a period of weeks, these cells gradually acquire features of mature neurons (Deng et al. 2010). As described in the section "Bottom-up: characterization of adult-born granule cells," charting how the phenotype of immature abGCs develops and how each developmental stage might offer the DG a functionally unique subpopulation of neurons through which to encode information is a major focus of research.
It is striking that the vast majority (80\%-90\%) of abGCs die before integrating into the DG circuit, with abGCs having to pass through a number of developmental stages where they are particularly vulnerable to apoptosis (Zhao et al. 2010a; Ming and Song 2011). Around half of newborn cells die within $4 \mathrm{~d}$ of mitosis and are then lost at a lower rate (Sierra et al. 2010). Around 3-wk postmitosis, NMDA receptor signaling is required for cell survival (Tashiro et al. 2006). Cell survival is just one aspect of adult neurogenesis that is susceptible to regulation by local activity, for example activation of $\mathrm{GABA}_{\mathrm{A}}$ receptors by ambient GABA in the first post-mitotic week influences dendritic arborization (Ge et al. 2006). In addition, cell proliferation rates and the rate at which abGCs mature in terms of dendritic outgrowth and gene expression are affected by the animal's environment and experience (Dranovsky et al. 2011; Piatti et al. 2011).

Overall, the factors that have now been described as influencing one or more aspects of adult hippocampal neurogenesis are numerous, including living in an enriched environment (EE) (Kempermann et al. 1997), exercise (van Praag et al. 1999), stress (Gould et al. 1997), antidepressant treatment (Malberg et al. 2000; Wang et al. 2008), psychiatric disease-associated mutations (Kvajo et al. 2008), social interaction (Fowler et al. 2002), and administration of drugs of abuse (Eisch et al. 2000). Whether all these factors converge on a common proximal effector, or if they act via distinct pathways (e.g., interneuron activity, glutamatergic input, trophic factors, signals from the vasculature, etc.) remains to be determined (see Faigle and Song 2013). And importantly, if and how altered neurogenesis has functional consequences for the animal exposed to these interventions is not always clear; in certain instances abGCs are required for specific aspects of the resultant behavioral changes (e.g., for antidepressant responses, Santarelli et al. 2003), but this is not always the case (e.g., enriched environment, Meshi et al. 2006; David et al. 2009).

Adult neurogenesis is a distinctive form of neural plasticity for numerous reasons. Among them is the fact that experience today will influence the number of potential new functional units available to the animal weeks later. Each abGC has key properties distinct to those of its mature neighbors, and these properties (e.g., excitability, synaptic physiology, connectivity) change over time while the new neuron is present in a functioning brain 
circuit. Moreover, each abGC can be viewed as a "blank canvas." Although we are far from understanding how the previous utilization of a neuron or a synapse in information processing impacts its future use, it is unique in the adult brain that for a period abGCs have never been used in previous information processing. And finally, the DG is the only brain structure where the network of existent neurons must adapt to the addition of new principal neurons; a process that has received little attention.

\section{Why does neurogenesis persist in the mammalian dentate gyrus in adulthood?}

Most attempts to answer this question have taken one of two approaches. The first is a "bottom-up" approach whereby the properties of abGCs are characterized and contrasted to those of matGCs in a bid to identify distinguishing features of these cells that would offer unique computational possibilities for the DG circuit. The second is a "top-down" approach in which the process of adult neurogenesis is altered in some way and the resultant effects on behavior are collated. As will be discussed in "Conclusions: toward a circuit-based understanding of adult hippocampal neurogenesis," bottom-up and top-down methodologies must ultimately converge in a consistent way if a satisfactory theory of the function of adult hippocampal neurogenesis is to be developed.

\section{Bottom-up: characterization of adult-born granule cells}

Studies aimed at determining how abGCs in the adult DG differ from their mature counterparts have largely employed ex vivo slice electrophysiology plus morphological analysis of abGCs. The essential technical advances in this arena have been methodologies that allow the selective visualization of individual abGCs, the major breakthrough being the development of retroviruses for introducing transgenes selectively into dividing cells (van Praag et al. 2002). By allowing the specific identification of neurons generated at the time of virus administration, this technique allows the characterization of living or fixed neurons of known age (see Box 3).

Below, to consider adult neurogenesis in the context of the DG, the summarizing of different aspects of developing abGCs' biology will be interleaved with discussion of matGCs' structure and function.

\section{Intrinsic properties}

Dentate GCs have a resting membrane potential of around $-80 \mathrm{mV}$. This rather hyperpolarized value has been observed in both slice preparations (Spruston and Johnston 1992; Staley et al. 1992; Kvajo et al. 2011) and in vivo in anaesthetized rodents (Penttonen et al. 1997). As their action potential threshold is around $-45 \mathrm{mV}$, GCs must be depolarized $\sim 35 \mathrm{mV}$ to fire. Although the input resistance of GCs is higher than that of pyramidal neurons (typical estimates range $\sim 230-450 \mathrm{M} \Omega$ [Spruston and Johnston 1992; Staley et al. 1992; Kvajo et al. 2011]), these cells still require large depolarizing currents to fire. Based on dendritic recording in ex vivo slices, GCs were found to lack dendritic amplification mechanisms, and were estimated to require (not accounting for inhibition) about 55 simultaneously active excitatory inputs to reach threshold (Krueppel et al. 2011).

The intrinsic properties of abGCs all begin at immature values and gradually shift toward matGC values over the first 4- to 6-wk post-mitosis (Fig. 2; see Deng et al. 2010). For example, abGCs initially have depolarized resting membrane potentials (around $-40 \mathrm{mV}$ at 1-wk post-mitosis, and hyperpolarizing linearly by $\sim 10 \mathrm{mV}$ per week [Ge et al. 2006]), high levels of intracellular chloride, and very high input resistances ( $>1 \mathrm{G} \Omega$ for the first 3 wk then falling to matGC levels over the fourth week [Mongiat et al. 2009]). This hyperexcitable state may be important for responding to ionotropic cues important for neuronal maturation at early stages (Ge et al. 2006). abGCs are capable of firing action potentials from around a week of age (Espósito et al. 2005), although early on action potentials are of blunted amplitude and wide, and have a substantial contribution from T-type $\mathrm{Ca}^{2+}$ channels (Schmidt-Hieber et al. 2004). After 3-wk post-mitosis abGCs are capable of firing spike trains in response to sustained depolarization and they are genuinely hyperexcitable, i.e., lower current threshold for spiking and greater overall spiking than matGCs, around the fourth week post-mitosis (Mongiat et al. 2009).

\section{Afferent synaptic connectivity}

The dendrites of GCs fan out in the molecular layer where they receive three primary bands of excitatory input. The innermost dendritic portions are innervated by mossy cell axons from the contra- and ipsilateral DG, the middle molecular layer contains afferents from the medial EC, and lateral EC afferents run through the outer third of the molecular layer (see Spruston and McBain 2007). GCs do not mutually innervate one another. In addition, GCs receive robust GABAergic input from a range of interneurons; they are perisomatically targeted by PV-expressing basket cells, receive a band of inputs from CCK-expressing basket cells on their proximal dendrites (Hefft and Jonas 2005), and are dendritically targeted by HICAP (hilar commissural/association pathway associated) and HIPP (hilar perforant-pathway associated) interneurons (for reviews, see Buhl and Whittington 2007; Houser 2007). In addition, GCs display a tonic inhibitory current in response

BoX 3. Identifying and manipulating adult-born granule cells for functional characterization

A number of early electrophysiological studies of abGCs filled recorded neurons and identified these cells as adult-generated by post-hoc analysis of either their morphology (e.g., limited dendritic complexity [Wang et al. 2000]) or immunoreactivity for a marker of young neurons (e.g., PSANCAM [Schmidt-Hieber et al. 2004]). The most significant advance in this domain was the demonstration by van Praag et al. (2002) that retroviruses carrying transgenes can be used to selectively incorporate those genes into the DNA of dividing progenitor cells. By locally injecting such viruses into the DG a significant fraction of neurons being generated for a short time thereafter are labeled and hence "birth-dated," so that subsequent recordings of labeled cells can correlate functional data with a precise cell age (e.g., Espósito et al. 2005; Ge et al. 2007).

Other identification strategies include transgenic mice where certain promoters direct expression of fluorescent proteins in abGCs at specific phases of their development, e.g., POMC-eGFP up to 2-3 wk (Overstreet et al. 2004) and GAD-67-GFP up to 3-4 wk (Zhao et al. 2010b), or where inducible Cre-recombinase expression in neural stem cells combined with a Flx-stop fluorescent reporter gene can be used to label abGCs born after induction (Dranovsky et al. 2011).

The ability to engineer retroviruses that deliver a shRNA directed against a gene of interest, in addition to a reporter protein, allows the consequences of knocking that gene down on abGC function to be assessed (e.g., Duan et al. 2007). Given concerns about off-target effects of shRNA (Kaelin 2012), a complementary strategy is the use of inducible NSC-specific Cre-recombinase in animals carrying floxed genes of interest (e.g., Kheirbek et al. 2012a; Pun et al. 2012). 


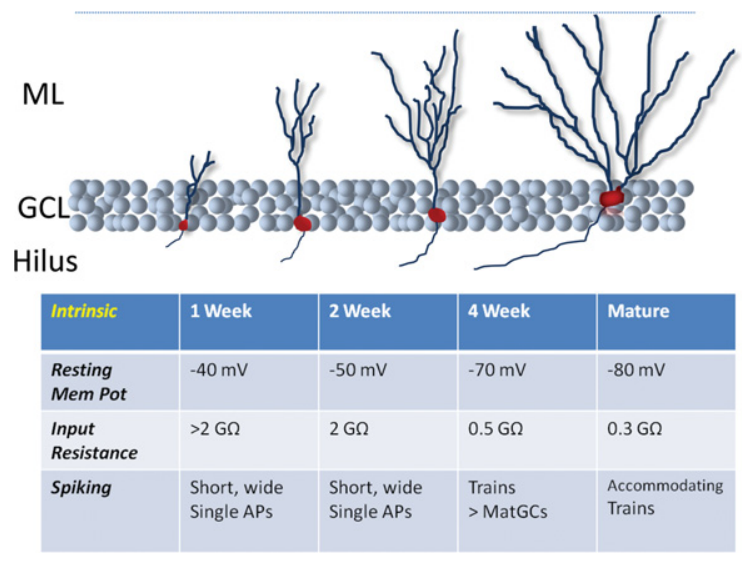

Figure 2. Development of abGC intrinsic properties. Before $2-3 \mathrm{wk}$ of age abGCs have substantial excitability (very high input resistances, low resting membrane potentials) but can fire only single blunted action potentials. Around the fourth week post-mitosis they have greater intrinsic excitability and fire trains of action potentials. (AP) Action potential.

to ambient GABA levels in the extracellular space (see Coulter and Carlson 2007).

The order in which these inputs become functionally connected to abGCs has been the subject of considerable study (Fig. 3; see Toni and Sultan 2011). Within days of birth abGCs express, as indicated by responsiveness to exogenously applied ligand, functional ionotropic glutamate and GABA receptors (Espósito et al. 2005; Overstreet-Wadiche et al. 2005), and $\mathrm{GABA}_{\mathrm{A}}$ receptors mediate a tonic conductance in response to ambient GABA (Ge et al. 2006). The first synaptic inputs to abGCs are received $\sim 1-$ 2 wk post-mitosis and they are slow, GABAergic IPSCs (Espósito et al. 2005; Overstreet-Wadiche et al. 2005) originating from neurogliaform cells (Markwardt et al. 2011). GABA is depolarizing at this time (due to immature, high internal chloride concentration), but when exogenously applied inhibits cell firing via shunting (Overstreet-Wadiche et al. 2005). (Interestingly, because of their hyperpolarized resting potential, GABA is also depolarizing and shunting in matGCs [Chiang et al. 2012; Sauer et al. 2012]). The final event in GABAergic innervation of abGCs, occurring at $\sim 3$-wk post-mitosis, seems to be functional connectivity to perisomatic basket cells that mediate large, fast IPSCs (Espósito et al. 2005).

Dendritic spines (Zhao et al. 2006) and functional glutamatergic synaptic input (Espósito et al. 2005) begin to appear 2-3 wk after mitosis, develop rapidly in the fourth week, but continue to accumulate to mature levels over a period of months (Toni et al. 2007; Mongiat et al. 2009). Toni et al. (2007) provided evidence that new afferent synapses develop by dendritic filopodia of abGCs invading preexistent synapses on matGCs, so that a transient "multisynapse bouton" exists before the matGC retreats.

The rate of abGC dendritic and afferent synaptic development varies along the dorsoventral axis of the DG (Piatti et al. 2011; Snyder et al. 2012) and can be modulated by antidepressant treatment (Wang et al. 2008) and the animal's environment (Piatti et al. 2011).

Overall, these studies of afferent innervation demonstrate that over the first $4 \mathrm{wk}$ of their life abGCs go through a dynamic program of synaptogenesis that, in many ways, recapitulates the developmental wiring of matGCs but at a slower rate (Liu et al. 1996; Overstreet-Wadiche et al. 2006). Therefore, immature abGCs are synaptically driven in ways distinct from matGCs in this period.

Whether mature abGCs and matGCs are, after this period, equivalently connected remains to be definitively answered. In terms of overall GABAergic and glutamatergic input, abGCs after a month or so of age are increasingly hard to distinguish from matGCs (Laplagne et al. 2006; Toni and Sultan 2011). However, it will also be important to know the relative excitatory input from mossy cells vs. MPP vs. LPP, and neuromodulatory inputs at different stages of abGC development.

Complementary to physiological analysis, two new studies (Vivar et al. 2012; Deshpande et al. 2013) have employed a monosynaptic retrograde tracing system, based on rabies virus (Wickersham et al. 2007), to label presynaptic partners of abGCs. Both studies demonstrated that early in their development abGCs are innervated by local GABAergic interneurons (located in the hilus, subgranular zone, GCL, and later the molecular layer) and hilar mossy cells. Each study also emphasized an early input from cholinergic septal neurons. Furthermore, both agreed on a later, accumulative labeling of neocortical inputs. The findings of Deshpande et al. (2013) were consistent with abGCs gradually acquiring a cohort of presynaptic partners of the same types as matGCs, although the results indicated that abGCs are robustly connected to the local DG circuit before they are connected to cortex. Conversely, Vivar et al. (2012) made three provocative claims, supplying evidence that abGCs (1) transiently receive input from matGCs, (2) receive no (or very little) input from medial $\mathrm{EC}$, and (3) receive robust direct input from perirhinal cortex.

The idea that abGCs are not innervated by medial EC inputs seems at odds with studies showing that stimulation of the middle molecular layer (where medial EC afferents run and abGCs have abundant dendritic spines) evokes robust EPSCs in abGCs,

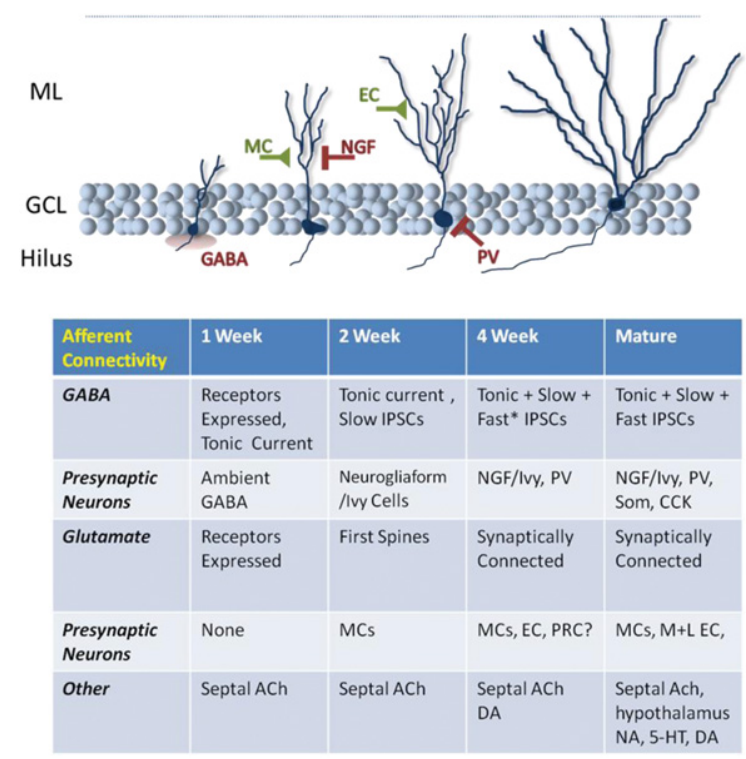

Figure 3. Development of abGC afferent innervation. abGCs undergo a complex program of afferent innervation over the first 4- to 6-wk postmitosis. At early time points they respond to ambient neurotransmitters, then they are progressively innervated by GABAergic and glutamatergic inputs, first locally and then by distal inputs. Hence, at different ages abGCs differ significantly from matGCs in terms of synaptic drive; whether the two GC classes ultimately converge in terms of afferent connectivity or whether they differ qualitatively is currently under debate. matGCs are known to receive significant input from hypothalamic/supramammillary afferents and varied neuromodulatory systems, the development of which in abGCs has yet to be extensively studied. (NGF) Neurogliaform cell; (NA) noradrenalin; (DA) dopamine; $\left(^{*}\right)$ "fast" IPSCs are present but these synaptic inputs are still significantly slower than such events in matGCs (Marín-Burgin et al. 2012). 


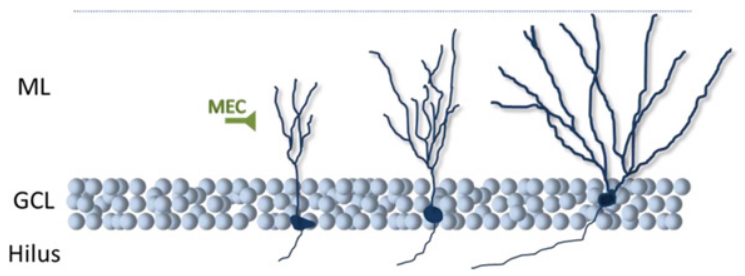

\begin{tabular}{|l|l|l|l|l|}
\hline Afferent LTP & 2 Week & 4 Week & 6 Week & Mature \\
\hline LTP & Weak & High & Medium-High & Medium \\
\hline Threshold & Lower? & Lower & $?$ & Higher \\
\hline NR2B & $?$ & High & $?$ & Low \\
\hline $\begin{array}{l}\text { GABAergic } \\
\text { Control }\end{array}$ & $?$ & Negligible & $?$ & Substantial \\
\hline
\end{tabular}

Figure 4. Synaptic plasticity at abGC afferents. Convergent lines of evidence support the notion that excitatory synapses onto abGCs (nearly always studied via stimulation of the medial molecular layer, i.e., presumed medial perforant path afferents) have a lower threshold for LTP and potentiate to a great degree when the cell is 3-6 wk of age. This is due to a number of factors including less pronounced GABAergic inhibition and greater expression of the NR2B subunit of the NMDA receptor.

and Kumamoto et al. (2012) have published that optogenetic stimulation of medial EC afferents produced EPSCs in abGCs. Nevertheless, these interesting data deserve further investigation as a qualitative difference between abGCs and their mature counterparts would represent a major focus for determining what unique functions adult neurogenesis might contribute to the DG.

\section{Afferent synaptic plasticity}

When Bliss and Lomo (1973) first described activity-dependent strengthening of synapses they did so at perforant path (PP) to DG synapses and much subsequent research has examined synaptic plasticity at this locus. Investigators interested in adult neurogenesis have likewise paid significant attention to the idea that abGCs and matGCs differ in afferent synaptic plasticity (Fig. 4).

In 2000, Wojtowicz and colleagues (Wang et al. 2000) published data from whole-cell recordings of GCs in the inner or outer GCL, which were ascribed to immature abGC or matGC categories, respectively. Glutamatergic inputs to immature abGCs underwent robust long-term potentiation (LTP) in response to high-frequency stimulation (HFS) of the molecular layer in control conditions (i.e., with inhibitory neurotransmission intact). Conversely, inputs to matGCs were not strengthened under such conditions, and even following $\mathrm{GABA}_{\mathrm{A}}$ receptor blockade, LTP in matGCs was not consistently observed. GABA $A_{A}$ blockade did not impact LTP in abGCs. A second induction protocol based on postsynaptic depolarization to $-20-\mathrm{mV}$ and $2-\mathrm{Hz}$ input also evoked greater synaptic potentiation in abGCs.

This group later recorded LTP of PP-evoked field EPSPs in the molecular layer and showed it to be: (1) modest under control conditions $(\sim 10 \%)$, (2) sensitive to an antagonist of NR2B-containing NMDA receptors, the NMDA variant typically expressed preferentially in development, (3) dependent on neurogenesis, and (4) significantly larger when inhibitory transmission was blocked, and this LTP was insensitive to the loss of adult neurogenesis (Snyder et al. 2001). Points (1), (3), and (4) are now wellreplicated findings (Saxe et al. 2007; Wang et al. 2008; Garthe et al. 2009; Massa et al. 2011) and a study in which NR2B was genetically deleted from abGCs recently found that LTP was absent in DG field recordings (Kheirbek et al. 2012a).
Schmidt-Hieber et al. (2004) made whole-cell recordings from young abGCs (PSA-NCAM immunoreactive) and matGCs and applied three different LTP induction protocols where $\theta$-burst afferent stimulation was paired with distinct regimes of postsynaptic depolarization (all in the presence of a GABA $\mathrm{A}_{\mathrm{A}}$ antagonist). The weakest protocol induced LTP in neither population, whereas the strongest did in both cell types. However, the intermediate protocol was effective only in abGCs, indicating these cells have a lower threshold for LTP induction.

Ge et al. (2007) confirmed and extended how NR2B receptor subunits contribute to enhanced abGC plasticity. Using the intermediate protocol of Schmidt-Heiber et al. (2004) (hence favoring LTP in abGCs) and working with $\mathrm{GABA}_{\mathrm{A}}$ receptors blocked, potentiation was maximal $4-6$ wk post-mitosis and by 2 mo was equivalent to the lower levels observed in matGCs. This LTP was blocked by an NR2B antagonist and the temporal profile of potentiation with respect to cell age paralleled the functional expression of NR2B-containing NMDA receptors. These authors also reported that leaving $\mathrm{GABA}_{\mathrm{A}}$ transmission intact does not impact LTP in 1-mo-old abGCs but entirely suppresses potentiation in 2-mo-old abGCs (Ge et al. 2008).

Last, in slices from mice where adult neurogenesis had previously been suppressed, the modest field potential long-term depression (LTD) that occurs in the DG was absent, as was LTP, and both forms of plasticity returned after neurogenesis was allowed to recommence in the animal. Interestingly, plasticity was normal when neurogenesis had only been unsuppressed for 2 wk (Massa et al. 2011).

Hence, in vitro studies indicate that for a time-limited period abGCs' afferent synapses are more plastic than those of matGCs. Specifically, for a period $\sim 4$ wk after birth a confluence of factors (less robust GABAergic innervation, robust expression of NR2B-containing NMDA receptors, and, potentially, expression of T-type calcium channels) allows a greater degree of synaptic plasticity to occur. Whether enhanced LTP involves strengthening functional synapses or the unsilencing of immature synapses has yet to be established.

The only in vivo study of LTP related to adult neurogenesis, however, found that field EPSP LTP was equal $15 \mathrm{~min}$ and $1 \mathrm{~d}$ after induction in the DG of control and neurogenesis-ablated animals. Interestingly, over $2 \mathrm{wk}$ the EPSP returned to baseline in controls, but in ablated mice enhanced EPSPs were maintained for 2-3 wk (Kitamura et al. 2009). The mechanisms by which abGCs promote depotentiation remain to be determined but interestingly, DG LTP in vivo is prolonged by blocking NMDA receptors, suggesting that depotentiation is an activity-dependent process (Villarreal et al. 2002) perhaps implicating abGCs in promoting overall DG activity levels.

The contradiction between in vivo and ex vivo findings should be taken in the context of a multitude of papers that have evoked robust LTP in vivo in the DG of awake or anesthetized rodents (e.g., Bliss and Lomo 1973; Villarreal et al. 2002; Kitamura et al. 2009). Studies using slice preparations have unequivocally shown differences in synaptic plasticity between young and mature GCs, but caution must be exercised in interpreting data that have suggested matGCs are incapable of undergoing LTP or LTD. It is possible that a permissive signal (such as a neuromodulator or mossy cell input) is lost during slice preparation or that inhibitory pathways are more strongly recruited when stimulating slices, for instead of stimulating the molecular layer directly, it is standard to excite the PP outside of the hippocampus in the intact animal.

Finally, few studies have reported the firing behavior of neurons during LTP induction, except for Schmidt-Hieber et al. (2004) who showed that when matGCs spike robustly they undergo pronounced LTP. As is the general case with LTP studies, how the 
protocols used to induce it compare to the inputs that neurons receive in vivo is uncertain and it remains to be determined if natural input patterns fall in the realm of inputs to which matGCs and abGCs are differentially sensitive.

\section{GC recruitment during information processing}

During a given experience, only a subset of hippocampal cells, in any subfield, is active, and in the DG the fraction of cells recruited is very small. Studies of immediate early gene (IEG) induction, using immunohistochemistry or in situ hybridization, have consistently shown distinctively sparse activation of GCs by behavioral experience. Studies that have examined c-fos, arc, or zif2568 expression after rodents have explored novel environments (Chawla et al. 2005; Ramírez-Amaya et al. 2005; Drew et al. 2011), undergone fear conditioning (CA Denny, pers. comm.), learned an active place avoidance task (Burghardt et al. 2012) or alternating T-maze (Satvat et al. 2011) all show a low percentage, $2 \%-5 \%$, of GCs expressing the activity marker relative to home cage controls where levels are typically $1 \%-2 \%$. Similarly, investigations employing in vivo electrophysiology report low activity in the GCL and sparse firing (see Box 2).

Determining the factors that select which neurons are recruited at any one time to encode an experience remains an essential goal of hippocampal research (e.g., de Almeida et al. 2009; Epsztein et al. 2011; Lisman 2011; Ziv et al. 2013). The sparseness of DG activity presents its own problems; if active cells are the most likely to undergo strengthening of their input synapses, a positive feedback loop might be created that favored the repeated recruitment of previously active cells because of the LTP they underwent (Lisman 2011).

However, recent work using novel IEG-based transgenic techniques to address GC recruitment by experience suggests that the DG has evolved mechanisms to avoid such a feedback loop. Although using IEG expression restricts the investigator to a binary classification of previously active or inactive (i.e., the rate, pattern, and spatial selectivity of firing is not captured), these studies reveal important information on which cells had been recruited during specific behavioral experiences.

Using indelible induction of YFP expression via inducible arc promoter-driven cre-recombinase expression, Denny (CA Denny, pers. comm.) found that reexposure to a context (in which the mouse was fear-conditioned) after $5 \mathrm{~d}$ activated a similar number of GCs but that only $6 \%$ of the originally active GC cohort were reactivated (in a second context reactivation was at chance, $\sim 2 \%$ ). Similar results were seen using a c-fos promoter-based system (Tayler et al. 2013). That exposure to the same context activated cohorts that were largely nonoverlapping with the original cohorts (i.e., $>90 \%$ of the activated neurons were not activated on the first exposure) suggests that, at least after a number of days, the same sensory experience is encoded by largely nonoverlapping populations, i.e., pattern separation is high. (Whether the locus of this separation is within the DG or reflects altered EC activity remains to be determined.)

Satvat et al. (2011) used subcellular zif268 mRNA localization to determine which GCs had been active in two experiences with less temporal separation (nuclear, active 5 min previous; cytoplasmic, $25 \mathrm{~min}$ ). When an animal entered the same environment twice there was a 70\% reactivation of the original GC cohort. Interestingly, these authors found that employment of a distinct search strategy (egocentric left-right vs. allocentric east-west) in the same environment halved the number of reactivated GCs. These results suggest that behavioral strategy impacts the active cells in the DG and, together with other studies, that there is a temporal component to the chances of experience reactivating a given GC.
As a fuller understanding of how the DG processes information is developed, essential questions in neurogenesis research include:

Does natural experience drive activity in abGCs and, if so, at what age are these cells first meaningfully active?

Are abGCs recruited to the active GC population at a level greater, less than, or equal to matGCs?

Conversely, what proportion of GCs recruited to compute/ store an experience is from the abGC population?

Do abGCs, by virtue of their distinct physiology, make a unique contribution to information processing?

Are GCs generally and abGCs specifically required at all stages of memory encoding, storage, consolidation, and retrieval?

And ultimately how does activity of abGCs alter/benefit the operation of this circuit?

The Schinder group has published two studies that have looked at the relative activation (i.e., reaching action potential threshold) of abGCs of various ages vs. matGCs in response to stimulation of the medial molecular layer in ex vivo slices. Mongiat et al. (2009) studied these cells in the presence of GABAergic blockade and overall found fairly equivalent activation of matGCs and 3to 4-wk-old abGCs, with a weaker glutamatergic input to the latter being counteracted by their greater excitability.

To better approximate the natural situation Marín-Burgin et al. (2012) conducted a similar slice study with inhibition intact. In this study, 4-wk-old abGCs were preferentially, over matGCs, recruited by EC afferent stimulation, due to delayed and slower feedforward perisomatic inhibition allowing for greater summation of excitatory inputs. In support of this, abolishing $\mathrm{GABA}_{\mathrm{A}}$ signaling, while facilitating spiking in matGCs, did not increase firing probability in young cells. Also, when two different sites in the molecular layer were stimulated separately, to model distinct afferent input patterns that might be expected from different experiences, 4-wk-old abGCs were more likely to spike to both inputs than matGCs were.

Li et al. (2012) made similar observations with 4-wk-old abGCs, demonstrating less inhibitory input and higher spike probability after molecular layer stimulation than 6- to 8-wk-old abGCs. They also similarly found no impact of blocking inhibition on spiking in 4 -wk-old abGCs.

Studies of abGC activation in the intact brain have thus far relied on detection of IEGs. The Frankland lab has addressed this question in two studies where abGCs were birth-dated using genomic incorporation of halogenated deoxyuracil and then the number of these cells expressing c-fos or arc after Morris Water Maze (MWM) learning was assessed. This fraction was then compared to the number of c-fos or arc-positive cells in either the overall GC population (Kee et al. 2007) or to a fraction of labeled matGCs achieved by injecting a different halogenated deoxyuracil compound perinatally (Stone et al. 2011).

Kee et al. (2007) concluded that 6- to 8-wk-old abGCs were preferentially incorporated into active cohorts $(4 \%-5 \%$ of abGCs vs. $2 \%$ of unlabeled GCs expressed an IEG). However, Stone et al. (2011) were unable to substantiate this claim using the refined methodology, finding equal levels of IEG expression in neurons generated and labeled in development or in adulthood. A recent study by Gu et al. (2012) also only found sparse c-fos labeling of retrovirally labeled 4 -wk-old abGCs ( $\sim 5 \%)$ after fear conditioning but this was not compared to levels in matGCs.

Overall, these data suggest that even in their hyperplastic phase, abGCs are recruited in a sparse pattern, similar to matGCs, and so at any one time the majority of active GCs will be drawn from the matGC pool. These studies, of course, assume that in abGCs neural activity is similarly coupled to IEG induction 
(but see, for example, Kuipers et al. 2009). And it should be noted that Snyder et al. (2009) while confirming low levels of IEG expression by mouse abGCs found that immature abGCs in rats were recruited at markedly higher rates.

Finally, Lemaire et al. (2012) analyzed dendritic branching in abGCs 2- and 4-mo post-mitosis and showed that MWM learning increased complexity even at these relative mature ages. The arbors of matGCs were not affected by learning, suggesting that abGCs' heightened plasticity is maintained long term in vivo.

This paper is interesting because, despite evidence that only a small proportion of abGCs are activated when learning the MWM (Kee et al. 2007), a significant shift in the average dendritic complexity was observed across the entire population of abGCs, suggesting that learning impacted all abGCs. Therefore, the signaling pathways activated, apparently globally and distinct from prototypic IEGs, by the learning experience remain to be determined.

Overall, the behavior of abGCs at distinct developmental stages in vivo remains opaque. To conclusively define if and how abGCs behave differently from matGCs, parallel characterization of the two populations' activity in awake-behaving animals will be required. We envisage that shortly the use of either in vivo single-unit electrophysiology (Leutgeb et al. 2007; Neunuebel and Knierim 2012) or in vivo population-activity imaging (Dombeck et al. 2010) coupled with genetic tools for identifying and/or manipulating abGCs and matGCs will shed significant light on these questions.

\section{Efferent synaptic connectivity and plasticity}

Many characteristics of GC MFs are unique or unusual (Henze et al. 2000):

1. Each GC has strikingly few large mossy terminals, which terminate on postsynaptic thorny excrescences (i.e., large multiheaded spines). Each GC innervates only, on average, 10 mossy cells and 12 CA3 pyramidal neurons, whereas each CA3 pyramidal neuron receives input from $\sim 40-50$ MFs (Henze et al. 2000; Spruston and McBain 2007 and references therein). By contrast, small en passant synapses and filopodial extensions made onto GABAergic INs are more numerous by a factor of 10 (Acsády et al. 1998).

2. MF terminals are large (4-10 $\mu \mathrm{m}$ across) and have multiple active zones (in some cases over 30), suggesting that an individual GC axon can powerfully activate a CA3 pyramidal neuron (see Henze et al. 2000).

3. Release probability at the MF-pyramidal neuron synapse is highly dynamic, being very low for an isolated action potential but facilitating hugely (up to 500\% increase in postsynaptic responses) upon repeated stimulation (see Nicoll and Schmitz 2005). Furthermore, facilitation occurs at both high and remarkably low GC firing frequencies (down to $0.2 \mathrm{~Hz}$; Salin et al. 1996).

4. MFs undergo a robust form of LTP that is nonassociative, i.e., potentiation is presynaptically induced and expressed (see Nicoll and Schmitz 2005), and is independent of postsynaptic NMDA receptor activation (Harris and Cotman 1986; although see Kerr and Jonas 2008).

5. In addition to glutamate, MF terminals contain, and presumably release, a number of other substances including GABA, dynorphin, and zinc (see Spruston and McBain 2007).

The functional implications of all of these features, and how they each mature in abGCs, are important for assessing DG function and how it is impacted by adult neurogenesis.
In a technical tour de force, Henze et al. (2002) showed that the firing of an individual GC (controlled via a patch pipette in vivo) was able to induce spiking in a subset of CA3 pyramidal neurons (simultaneously recorded using an extracellular electrode) or significantly increase their firing rate. Critically, however, this effect was dependent on GCs firing multiple action potentials in a train. Such robust excitatory drive to a CA3 pyramidal neuron from a single GC is theoretically attractive for such a sparsely active and sparsely connected structure as the DG, as each CA3 pyramidal neuron (with only $\sim 40$ MF inputs) has a very low probability of receiving convergent input from two simultaneously active GCs.

Hence, the first three points above suggest that the repetitive firing of an individual GC will strongly activate a group of 10-15 CA3 pyramidal neurons while also increasing general inhibitory tone in CA3 through its numerous inputs to INs (Lawrence and McBain 2003). Concurrently driving activity in a cluster of CA3 pyramidal neurons might promote the functional coupling of these cells during memory formation by acting as an instructive signal for associative synaptic strengthening at CA3-CA3 collateral (Kobayashi and Poo 2004) or EC-CA3 synapses. Although a "back-projection" from CA3 pyramidal neurons to hilar INs may influence which GCs become active (Myers and Scharfman 2011), that LTP at MF-CA3 pyramidal neuron synapses is nonassociative, and can be induced by stimulation patterns based on natural GC firing patterns (Gundlfinger et al. 2010), suggests that the recruitment of GCs by EC input determines which CA3 pyramidal neurons receive strong DG drive, independent of CA3 activity.

In addition to functional synaptic plasticity, MFs also display pronounced structural plasticity. At the gross level, MF outgrowth in CA3 was observed after tetanic stimulation of the PP (Adams et al. 1997) and after training in the MWM MFs expanded their terminal fields considerably, in particular MFs invaded CA3 stratum oriens (Ramirez-Amaya et al. 2001; Rekart et al. 2007; McGonigal et al. 2012). MFs can also sprout into the molecular layer, but this is thought to occur only in pathological conditions such as epilepsy (Tauck and Nadler 1985; Sutula et al. 1989; Nadler 2003).

Galimberti et al. (2006) found large mossy terminals to be a diverse set of synapses that were larger and more complex when animals were housed in an enriched environment. Moreover, in organotypic slice cultures this class of synapse was highly dynamic, with synapses forming and dismantling over time. Additionally, Ruediger et al. (2011) saw that contextual and spatial learning led to a substantial increase in the number of MF filopodia synapsing onto CA3 interneurons.

Together, these studies suggest a system where the connectivity between DG and CA3, rather than being fixed, is highly dynamic with axons and their terminals growing and morphing to significantly change network structure.

Detailed analysis of the structural development of abGC axons (Fig. 5) lags behind the study of their dendritic maturation and, in particular, its regulation by extrinsic factors has not been investigated. In standard-housed mice, by $\sim 1$-wk postmitosis there is significant axonal invasion of CA3 (Zhao et al. 2006; Faulkner et al. 2008; Ide et al. 2008). However, electron microscopy studies addressing when these axons generate functional synapses have generated somewhat discordant results. Ide et al. (2008) observed that 1-wk post-mitosis MF boutons expressed vGlut1 and on occasion formed rudimentary synapses on dendritic shafts, whereas 2-wk-old MFs formed complex synapses that differed little from mature ones. Faulkner et al. (2008), however, found that 2-wk-old terminals are immature and only become relatively complex at $4 \mathrm{wk}$, with continued maturation over the next 3 mo. 


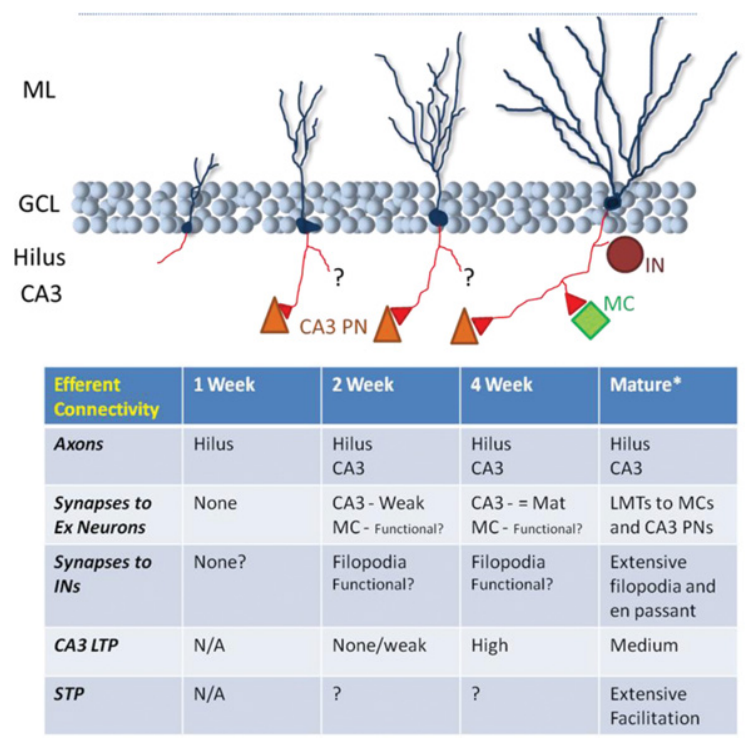

Figure 5. Development of abGC efferent axons. abGCs appear to be well connected to their target cells in CA3 and the hilus by the time they are strongly afferently driven and capable of firing trains of action potentials. When precisely their large mossy terminals (LMTs) are mature, based on microscopy studies, is a matter of some debate. Functionally, CA3 pyramidal neurons (PNs) receive weak glutamatergic inputs from 2-wk post-mitosis and at 4-wk synapses are, at basal levels, of mature strength and potentiate to a greater degree than mature (8-wk-old) abGCs. The functional coupling of young abGCs to the local hilar network is apparent from morphological studies but is functionally uncharacterized. (*) See Figure 1 for matGC connectivity.

Toni et al.'s (2008) earliest time point was 17 -d post-mitosis when young MFs mainly targeted CA3 pyramidal neurons' dendritic shafts. At 4 and $11 \mathrm{wk}$ they found that abGCs' MFs synapsed onto the thorny excrescences of CA3 pyramidal neurons. At 4 wk they shared these sites with unlabeled, presumably mature, MF terminals whereas at $11 \mathrm{wk}$ they were the sole presynaptic partner. Hence, a model of efferent synaptogenesis that echoes the one proposed for afferent innervation of abGCs is presented, where the young cells invade, share, and then take over preexistent synapses.

Each study noted that abGCs form smaller synapses onto INs, but focused on large boutons targeting CA3 neurons. Ide et al. (2008) showed that smaller synapses considerably outnumbered large boutons in both the hilus and CA3, with potentially a small overexuberance at $2 \mathrm{wk}$ of age that decreased by 9-wk postmitosis. (Although this analysis assumed that small synapses were specific IN targeting synapses and not an early developmental stage of large mossy terminals.)

Finally, although only working in the early postnatal weeks, Yasuda et al. (2011) found that newborn GCs would outcompete genetically silenced GCs born earlier in development for postsynaptic partners in CA3, suggesting that dynamic competition and rewiring can occur between newly generated and preexistent GCs.

To date, two functional studies of abGC output have been published, both employing retroviral delivery of the lightactivated cation channel channelrhodopsin 2 (ChR2) for abGC stimulation. Toni et al. (2008) recorded from putative postsynaptic neurons 3-4 mo after infection and observed optically evoked glutamatergic EPSCs in 15\% of recorded hilar interneurons, $6 \%$ of mossy cells, and $10 \%$ (one of 10) of CA3 pyramidal neurons.

Recently, Gu et al. (2012) recorded from CA3 pyramidal neurons while stimulating ChR2-expressing abGCs of various ages. EPSCs appeared at 2-wk post-infection, and increased to stable amplitude at $4 \mathrm{wk}$ (the proportion of CA3 pyramidal neurons innervated is not stated). $\theta$-burst and $50-\mathrm{Hz}$ stimulation of abGCs age-dependently induced LTP of field potential EPSPs in CA3, with plasticity maximal at 4-wk post-mitosis. Hence, efferent synaptic plasticity mirrored the "hyperplasticity" of abGCs' afferent synapses at this age.

With the functional innervation of CA3 by abGCs now wellconfirmed, it remains to be determined how abGCs select their target neurons-are the most active, least active, or simply random CA3 and hilar neurons targeted? This may be especially significant if the Toni et al. (2008) model is correct and innervation involves the elimination of preexisting synapses. Furthermore, how does the structural plasticity implemented by adult neurogenesis interact with the structural plasticity observed in matGCs? And does activity during their development impact abGC efferent synaptogenesis? Do all efferent synapses mature at the same rate, i.e., is output to hilar neurons and CA3 pyramidal neurons and INs regulated equally? And finally, given its large influence on synaptic transmission, does short-term plasticity at MF synapses change with cell age as it does in development (Mori-Kawakami et al. 2003)?

As stated above, ultimately DG function must be defined in terms of its impact on CA3 physiology. Two recent IEG studies cast light on CA3 activity in mice with reduced or ablated neurogenesis. Niibori et al. (2012), using combined arc immunohistochemistry (remote experience) and in situ hybridization (recent experience), found greater overlap in the CA3 pyramidal neurons activated by two similar environments (but not markedly different ones) when neurogenesis was reduced, i.e., less distinct representations were formed, indicative of reduced pattern separation. Denny et al. (2012) found that in neurogenesis-ablated mice that displayed poor contextual memory retrieval following brief encoding sessions (see "Contextual and spatial memory"), this was correlated with reduced reactivation of CA3 pyramidal neurons when mice were reexposed to the shock-associated context.

Again, we are excited by the prospect of in vivo physiological characterization of CA3 activity in animals lacking neurogenesis or when abGCs are modulated in some way, although we anticipate these experiments will be technically challenging, noting, for instance, the grossly normal CA3 physiology observed in a mouse lacking output from nearly all matGCs (Nakashiba et al. 2012).

\section{Top-down: behavioral effects of altering neurogenesis}

There is now a large body of work in which investigators have manipulated hippocampal neurogenesis in adults and tested for resultant behavioral changes. Ultimately, one would like a list of specific cognitive and affective processes that either require adult neurogenesis or are impacted by its presence. This literature, however, has to date implicated abGCs in a large array of cognitive domains and is not always consistent (for reviews, see Deng et al. 2010; Koehl and Abrous 2011; Marín-Burgin and Schinder 2012). In this truncated review of the behavioral literature we will highlight various emerging themes.

Most studies have employed methods to reduce or ablate the production of abGCs, and some have used techniques to increase production (see Box 4). Given that this is typically a chronic manipulation, such studies must consider if the animal may be able to employ alternative strategies to function in the experimental paradigm, if compensatory mechanisms might lessen the impact of ablating adult neurogenesis (e.g., Singer et al. 2011), or if there is redundancy in the abGC population when ablation is incomplete. Conversely, false positive results may arise if there are sideeffects associated with the ablation technique (see Box 4). Finally, even when the manipulation is specific, the ideal control group, the killing or silencing of $\sim 5 \%$ of matGCs, is unavailable. 
BOX 4. In vivo manipulation of adult neurogenesis

Early investigations of adult neurogenesis suppressed the generation of abGCs by systemic administration of antimitotic agents (e.g., methylazoxymthanol acetate [Shors et al. 2001], temozolomide [Garthe et al. 2009]), a treatment confounded by nonspecific DNA modification and the inhibition of cell division throughout the body. The next development was the employment of whole brain, then focal, X-irradiation whereby the brief application of X-rays selectively kills dividing cells (Parent et al. 1999; Peissner et al. 1999); this technique, however, is accompanied by widespread DNA damage (see Ford et al. 2011) and inflammation in adjacent tissue (Monje et al. 2002). Although experiments are typically conducted once side-effects have subsided, and a "sham" group is anesthetized, nonspecific effects cannot be controlled for. Consequently, efforts are ongoing to develop localized irradiation methods (Ford et al. 2011), although irradiation will still impact the entire DG.

Genetic techniques to ablate adult neurogenesis have also been developed. One model employs mice where Herpes virus thymidine kinase (which catalyzes the conversion of ganciclovir to a compound toxic to proliferating cells) is targeted to GFAP-expressing cells, which include subgranular zone radial glial-like cells, so that administration of ganciclovir (or valganciclovir) will suppress neurogenesis (Bush et al. 1998; Saxe et al. 2006; Denny et al. 2012). However, enteric glial expression of GFAP can give rise to gastric side effects (see Bush et al. 1998) if drug administration is not carefully titrated. Cell-targeting using the human GFAP promoter may help (Schloesser et al. 2009) but astrocytic proliferation is always arrested.

Dupret et al. (2008) overexpressed the proapoptotic gene Bax in neural progenitor cells by putting its expression under the control of the reverse tetracycline-controlled transactivator gene and driving this gene with the nestin promoter, which is expressed selectively in neural progenitors. Hence, administration of the tetracycline analog, doxycycline, increases subgranular zone apoptosis. However, neurogenesis is reduced rather than ablated in this model (Dupret et al. 2008; Massa et al. 2011).

Another confound to consider when ablating adult neurogenesis was highlighted by Singer et al. (2011) who found that although PP LTP was absent $4 \mathrm{wk}$ after ablation (see "Adult hippocampal neurogenesis and its regulation") it returned to control levels by 10-wk post-ablation. To account for this recovery, they showed that GABAergic innervation of matGCs decreases over time following ablation, suggestive of a chronic homeostatic/pathological change to the DG network.

Procedures to increase adult neurogenesis have focused largely on placing rodents in enriched environments with access to running wheels, whereby the exercise and elevated sensory stimulation increases neurogenesis considerably (Kempermann et al. 1997; van Praag et al. 1999). However, this technique also suffers from a lack of specificity, as it is well-established that EE has many significant effects throughout the brain, not least in the hippocampus (see van Praag et al. 2000). Demonstrating that EE effects on behavior are prevented by ablating neurogenesis is necessary before any such changes are attributed to this process (e.g., Meshi et al. 2006).

To date the only published genetic strategy for increasing the number of abGCs was by Sahay et al. (2011b) who deleted the Bax gene from neural progenitor cells (using the cre-lox system where cre-recombinase expression was driven by the nestin promoter) and observed more than twice the number of doublecortin positive neurons with tertiary dendrites.

Developing pharmacological strategies for selectively increasing adult neurogenesis remains a goal of the pharmaceutical industry; some initial success has been reported (Pieper et al. 2010) and this lead compound is currently being refined (MacMillan et al. 2011).

\section{abGCs and pattern separation}

The necessity of forming distinct memories of similar experiences is thought to require an encoding process whereby overlapping input patterns are somehow separated to be stored as more dissimilar patterns, hence facilitating their recall as distinct entities (see "The mammalian dentate gyrus"). By its formal definition (i.e., the transformation of similar inputs into more discordant outputs), pattern separation during memory encoding cannot be tested behaviorally. Rather, behavioral paradigms (based on both operant and associative learning) have been designed to assay the ability of animals to form distinct memories of similar spatial or contextual input sets (for discussion, see Hunsaker and Kesner 2013 ). The studies we describe below have combined more or less specific manipulations of the DG and/or adult neurogenesis with such behavioral tests, i.e., they have manipulated the structure in which pattern separation is hypothesized to occur and tested a predicted consequence of impaired pattern separation. Ideally, subjects would be tested on a spectrum of input patterns that vary parametrically (Hunsaker and Kesner 2013). More commonly, however, investigators have tested memory for cues or contexts that have been classified as similar or dissimilar, such that if responses to dissimilar inputs are unaffected the interpretation that it was a pattern separation operation that was compromised by the manipulation is strengthened.

There is now good behavioral support for the DG being critical in pattern separation (Kesner 2007, 2013; Hunsaker and Kesner 2013). Conversely, the mechanisms by which pattern separation is achieved remain uncertain. One hypothesis suggests that within a short period of time a stable subpopulation of active cells encodes differences in context via rate remapping (Leutgeb et al. 2007). However, originally the connectivity of the DG led to the proposal that patterns would be separated via recruitment of different GCs (i.e., global remapping; Rolls 1996; Rolls and Kesner 2006) and the results of Leutgeb et al. (2007) have recently been challenged (see Box 2; Neunuebel and Knierim 2012).

Behavioral tests largely rely on presenting animals with a novel neutral stimulus or stimulus location that resembles (to varying degrees) a stimulus or context previously associated with a reward or an aversive event, and determining if animals can distinguish the two stimuli. For instance, rats trained to push an object to access a sweet cereal pellet, when presented with that cup and a second empty one located at incrementing distances from the original, go to the correct one less frequently after a DG lesion only when the two objects are close together (Gilbert et al. 2001).

McHugh et al. (2007) exposed mice to two similar environments; in one, A, the animals were electrically shocked on each exposure, whereas in the second, $\mathrm{B}$, they never received the noxious stimulus. The A:B ratio of freezing was taken as an indicator of how well the animal had formed distinct representations of the two contexts (Frankland et al. 1998). When the obligate NMDA receptor subunit NR1 was deleted from GCs mice took longer to discriminate the two contexts. Additionally, in vivo recordings of CA3 pyramidal neurons spatial firing in two distinct contexts showed that rate remapping was significantly lower in mutant mice (although remapping in CA1 was unchanged; McHugh et al. 2007).

An essential role for abGCs in mediating pattern separation, as inferred from behavioral deficits in mnemonic discrimination, is now supported by convergent lines of evidence (Sahay et al. 2011a). In the context-discrimination task employed by McHugh et al. (2007), mice lacking neurogenesis (Sahay et al. 2011b), with 
reduced neurogenesis (Tronel et al. 2012), or lacking NR2B subunits in abGCs (Kheirbek et al. 2012a) all perform worse than controls. And in a complementary experiment, where Sahay et al. (2011b) increased the number of abGCs in the DG by deleting the essential proapoptotic gene Bax from neural stem cells and their progeny, mice discriminated between the two similar contexts more quickly.

Additionally, Clelland et al. (2009) tested mice in two spatial memory tasks after adult neurogenesis had been ablated using irradiation: (1) a radial arm maze task where mice had to choose the previously unvisited arm from two options spatially separated to varying degrees and (2) a nose-poke, touch screen task where a correct response from two choices presented at differing distances had to be made. In both cases irradiated mice performed worse than controls when spatially close choices were given but not when the options were well separated. Additionally, mice with elevated adult neurogenesis due to running also performed better on the touch screen task (Creer et al. 2010).

Finally, Nakashiba et al. (2012) aimed to silence DG output completely by expressing tetanus toxin light-chain in all GCs. However, the transgenic strategy employed led to the toxin not being expressed by abGCs until four or so weeks post-mitosis. Surprisingly, when mutant mice were tested in the contextdiscrimination task they distinguished the contexts faster than controls, suggesting, that abGCs alone mediate pattern separation in the DG, and that the large population of matGCs, in fact, hampers this process. Irradiating mutant and control mice impaired discrimination in a version of this task where the contexts were more dissimilar. These alterations were task-specific as mutant mice performed the radial arm task, used by Clelland et al. (2009), at control levels.

Interestingly, mutant mice displayed deficits in tasks hypothesized to be reliant on pattern completion, i.e., where memory of a context had to be retrieved based on a short exposure or when a hidden MWM platform had to be found when only a subset of cues present during learning was given during testing. This group had previously shown that mice lacking functional NMDA receptors in CA3 pyramidal neurons had deficits on such tasks (Nakazawa et al. 2002). The Nakashiba et al. (2012) study, thus, contradicts traditional models of hippocampal function by suggesting the DG is essential for both pattern separation and completion, with abGCs mediating the former and matGCs being required for the latter. However, it remains to be demonstrated whether ablation of mature cells was complete and whether a sparse number of remaining mature cells could function in these tasks.

Overall these studies suggest that abGCs are critical to an animal's ability to form distinct memories of similar inputs and to guide behavior accordingly, and are thus consistent with this cell population making a critical contribution to the DG's ability to execute pattern separation. Most controversially, the possibility is raised that abGCs alone are sufficient to mediate such a process. Given that the original conceptions of pattern separation relied on the activity of entorhinal cortical neurons being remapped onto a much larger number of DG GCs (see "The mammalian dentate gyrus") these observations invoke a need to develop novel circuit-based models to account for the function of both abGCs and matGCs in pattern separation (and completion).

\section{Contextual and spatial memory}

Beyond a specific role in pattern separation the DG has typically been considered a key player in the acquisition and encoding of spatial and contextual information by the hippocampus (see Rolls and Kesner 2006; Kesner 2007, 2013; Xavier and Costa 2009). Recently, using optogenetic manipulation of the entire
GC population that allowed transient and reversible excitation or inhibition, we found evidence that GCs are required for encoding of contextual memories but not for their retrieval (Kheirbek et al. 2013). Others have reported that selective optogenetic activation of GCs previously active during contextual encoding can later evoke a "false memory" but the requirement of these neurons for memory retrieval was untested (Liu et al. 2012). Using IEG labeling of activated GCs Satvat et al. (2011) have also provided evidence that different sets of GCs are recruited when animals are using an egocentric (e.g., turn left) or allocentric (e.g., turn east) strategy to run a maze, suggesting that, in addition to spatial input, task demands influence DG recruitment.

There are now many studies in which the impact of manipulating adult neurogenesis on hippocampus-dependent learning has been assessed. We refer the reader to recent extensive reviews of this literature (see Deng et al. 2010; Koehl and Abrous 2011; Marín-Burgin and Schinder 2012). As these reviews note, although basic deficits in contextual learning (assayed often by contextual fear conditioning) and spatial learning (usually as per the MWM) have been found, replication efforts have yielded divergent, often contradictory results. The reasons for these inconsistencies likely represent both meaningful variability in the task demands and biology of the subjects as well as confounds in the experimental methods used to alter neurogenesis (see Box 4).

With respect to specific task demands, for contextual fear conditioning both the time since ablation of neurogenesis (Denny et al. 2012) and the specific training paradigm used (Drew et al. 2010) are essential; these two studies provided evidence that 4- to 6-wk-old abGCs are crucial when contextual encoding is brief and only a single conditioning shock is given, suggesting the presence of abGCs may facilitate rapid acquisition of information. In the MWM, Dupret et al. (2008) found that changing subjects' starting positions in the maze on testing days resulted in impairment for ablated mice, suggesting that relational memory, the combining of self-position with external cues, requires abGCs. This group has also published work demonstrating that MWM learning promotes both the survival and apoptosis of abGCs depending on cell age, suggesting that learning involves an active reorganization and stabilization of DG circuitry (Dupret et al. 2007).

Burghardt et al. (2012) investigated a role for abGCs in cognitive flexibility by testing mice that lacked adult hippocampal neurogenesis in a rotating maze task in which animals had to learn to avoid a fixed shock zone (relative to external cues) while on a rotating disc. Ablated animals learned the task at control levels, but when the shock zone was changed ablated mice showed pronounced deficits in the ability to learn the new location. When the expression pattern of arc in the DG was examined after mice had undergone reversal learning, the number of activated cells was higher in ablated mice, consistent with network level deficits and the possibility that animals had two overlapping spatial representations active in the DG. Minor deficits in reversal learning in the MWM have also been suggested in animals lacking adult neurogenesis (Wojtowicz et al. 2008; Garthe et al. 2009).

To date, most behavioral studies have employed chronic ablation/supplementation models where the levels of abGCs are altered throughout the multiple phases of the learning paradigm (i.e., acquisition, encoding, storage, consolidation, and retrieval). However, newer techniques allow the quieting or activation of these cells in an epoch-specific manner.

Recently, the first study using in vivo optogenetics to manipulate abGC activity was published ( $\mathrm{Gu}$ et al. 2012). This study found that suppression of 4-wk-old, but neither 2- nor 8-wk-old, abGCs specifically during recall trials impaired contextual fear memories and spatial memories in the MWM. Interestingly, optically suppressing 4-wk-old abGCs during MWM training had no 
effect on memory acquisition. These results complement those of Arruda-Carvalho et al. (2011) where killing abGCs (using conditional expression of the diphtheria toxin receptor) prior to training had no effect on contextual fear or MWM learning but when abGCs were ablated between training and testing memory was impaired.

The most parsimonious explanation of these data is that the DG can compensate for the absence of abGCs if they are not present at the time of learning, even if they are typically employed in learning and are required for full recall. As such, while these results support a functional role for abGCs in spatial/contextual memory, they also suggest that a neurogenesis deficient hippocampus functions as well as a control one in these tasks (at least in the easier versions that were used in these studies) and therefore do not necessarily provide evidence toward the value of generating new neurons.

Finally, Kitamura et al. (2009) provided evidence that the presence of abGCs speeds the time in which contextual memories become independent of hippocampal activity. Four weeks after fear conditioning inactivation of the hippocampus by tetradotoxin infusion had no impact on freezing levels in control mice but partially inhibited freezing in ablated mice. Conversely, in mice with elevated abGC levels, due to running, memories more rapidly became hippocampus-independent. This paper would suggest that abGCs are important elements of memory consolidation and transfer to neocortex, however the mechanisms by which they function in this process are currently undefined.

Related to longer-term memory processing Josselyn and Frankland (2012) have proposed that neurogenesis may actively destabilize memories and hence promote forgetting. The authors cite the inverse correlation, through development, between rates of hippocampal neurogenesis and the ability to lay down longterm memories, and have found that promoting AHN postlearning diminishes the retrieval of previously established memories (Frankland et al. 2013). This intriguing hypothesis demands a fuller understanding of why the increase in neurogenesis associated with hippocampus-dependent learning tasks is advantageous to the animal but underscores the dynamic nature of hippocampal structure and function. Interestingly, theories of synaptic memory systems where new memories must be encoded by networks that already contain stored information emphasize that learning necessarily means data loss, or forgetting (see, for example, Fusi et al. 2005). Hence, if abGCs rapidly encode information they may do so in a way that impacts previously stored information.

Overall, behavioral studies have not generated a significant consensus so far. However, one may note that the contribution of adult neurogenesis is most pronounced when the task is difficult and requires either rapid encoding or fine discrimination. Some of the heterogeneity in the interpretations may stem from the fact that modulating the DG will impact the rest of the hippocampal circuit. For example altering encoding and/or pattern separation by the DG is likely to influence downstream information storage and hence affect pattern completion, forgetting, or the transfer of information out of the hippocampus.

\section{abGCs and affect}

The negative impact that stress has on the proliferation and survival of adult-born granule cells (Gould et al. 1992, 1997; Fowler et al. 2002; Mirescu and Gould 2006) has fueled interest in a link between adult hippocampal neurogenesis and affective behavior. Moreover, antidepressant treatments, including selective serotonin reuptake inhibitors (SSRIs), monoamine oxidase inhibitors, and electroconvulsive therapy, increase levels of abGCs in the adult DG (Malberg et al. 2000), and the SSRI fluoxetine in- creases the rate of maturation of abGCs (Wang et al. 2008). Critically, certain behavioral effects of antidepressants are absent in mice that lack the capacity for adult neurogenesis (Santarelli et al. 2003; Airan et al. 2007; Surget et al. 2011), for example neurogenesis is required for antidepressant-mediated changes in the novelty suppressed feeding assay but not the forced swim test (David et al. 2009).

By contrast, the contribution of neurogenesis to baseline mood and how alterations in this process might contribute to the etiology of affective disorders remains much more controversial (Becker and Wojtowicz 2007; Sahay and Hen 2007). Although Revest et al. (2009) found evidence that reduced AHN could lead to an anxious phenotype, most studies have found that ablation of neurogenesis did not alter affective phenotype per se (Santarelli et al. 2003; David et al. 2009; Kitamura et al. 2009; Sahay et al. 2011a; Snyder et al. 2011; Surget et al. 2011).

Schloesser et al. (2009) found that mice lacking adult neurogenesis released a greater amount of the stress hormone corticosterone in response to mild stress, indicative of abGCs functioning somehow to suppress the hypothalamo-pituitaryadrenal (HPA) axis. Snyder et al. (2011) further found that if mice without hippocampal neurogenesis were exposed to mildly stressful events they later demonstrated behaviors consistent with a greater stress response. Surget et al. (2011) found that chronic unpredictable stress induced disruption of the HPA axis that was reversed by fluoxetine in a neurogenesis-dependent fashion. Hence, there is increasing interest in the concept of abGCs being crucially involved in reactions to stressful events (Dranovsky and Leonardo 2012).

Currently the mechanisms by which antidepressants act through abGCs to improve mood and how abGCs modulate the HPA axis remain uncertain. There is increasingly a consensus that whereas the dorsal hippocampus is concerned with cognitive/spatial processing, the ventral pole operates in circuits that modulate affect (Fanselow and Dong 2010). Specifically, the ventral HPC projects to the whole limbic system (amygdala, nucleus accumbens, PFC, and hypothalamus) while the dorsal hippocampus projects primarily to association cortices (Fanselow and Dong 2010). Recently, through optogenetic modulation of GCs, we provided further support for this model, finding that grossly increased activity in the ventral DG selectively had an anxiolytic effect, whereas the dorsal DG was involved in general exploratory drive and memory encoding (Kheirbek et al. 2013). Airan et al. (2007) proposed a model of hippocampal pathology in a chronic stress model of depression whereby overall DG excitability is reduced relative to that of CA1 and antidepressants reverse this shift in a neurogenesis-dependent fashion. How precisely abGC activity might act to modulate, or repress, the HPA axis remains to be determined; it is possible that levels of neurogenesis directly impact the negative feedback loop mediated by stress hormones via hippocampal glucocorticoid receptors. Furthermore, how activity in the ventral hippocampus is related to the emotional valence of a situation, either encoding it directly (Royer et al. 2010) or significantly modulating downstream structures where valence is computed (Adhikari et al. 2011), awaits further elucidation.

That a robust link between adult hippocampal neurogenesis and mood exists without clear mechanistic insight is perhaps not surprising. How the routing of neuronal information through the dorsal portion of the hippocampal loop generates spatial maps and underpins episodic memory is a major focus in neuroscience (Buzsáki and Moser 2013), but our understanding of how an apparently homologous circuit (albeit with minor differences) in the ventral hippocampus processes affective information lags behind substantially. We believe a better understanding of this network will provide significant insight into mood and related disorders (Kheirbek and Hen 2011; Kheirbek et al. 2013). 


\section{Conclusions: toward a circuit-based understanding of adult hippocampal neurogenesis}

It is now clear that in most mammals the DG produces a significant stream of new cells every day and the work of Toni et al. $(2007,2008)$ suggests that it is a disruptive process, with abGCs invading and taking over both afferent and efferent synapses made by preexistent matGCs. Why the DG network can accommodate such disruption is the first question that must be answered and the second is why it benefits from such an arrangement.

Among the most striking features of the DG are its sparse activity, each GC's sparse connectivity to CA3 pyramidal neurons, the large synaptic strength of large mossy terminal synapses, the nonassociative nature of LTP at these synapses, and that GCs are not directly synaptically connected to one another (see "Bottomup: characterization of adult-born granule cells"). These features have important implications for information transfer from DG to CA3. Sparse activity and connectivity mean that at any time a given CA3 pyramidal neuron is unlikely to receive input from two active GCs. Hence, it is improbable that DG output relies on convergent drive from GCs and the high strength of GC-CA3 pyramidal neuron synapses may represent a necessary feature to allow the DG to robustly influence CA3. Moreover, potentiation of large mossy terminal synapses occurs in a GC autonomous fashion (i.e., is independent of the firing of other GCs or the target cell [Nicoll and Schmitz 2005; Barnes et al. 2010]).

Together these attributes suggest that the activity of an individual GC has a significant impact on CA3 processing (Henze et al. 2002), in contrast to information transfer from CA3 to CA1, say, where connections between pyramidal neurons are individually weak (Bolshakov and Siegelbaum 1995). The significance of this remains to be formalized but it suggests that the activity of single GCs might be important in the recruitment of specific CA3 pyramidal neurons during memory encoding and that reactivating that same GC (be it as part of consolidation or recall) is sufficient to reactivate its CA3 targets. In this context, the idea of abGCs being specialized units for long-term information storage acquired during their hyperplastic phase is challenged by the fact that efferent connectivity continues to evolve after that period (see "Efferent synaptic connectivity and plasticity"), meaning reactivation of a given cell might recruit novel downstream targets.

Building a specific understanding of how the DG contributes to all stages of mnemonic processing will be essential for fully understanding adult neurogenesis. Novel tools for specifically (McHugh et al. 2007; Nakashiba et al. 2012) and transiently (Liu et al. 2012; Kheirbek et al. 2013) manipulating the DG should allow us to disentangle the functions of the DG in memory encoding, storage, consolidation, and retrieval. Currently, much attention has been focused on the DG during memory encoding and its placement to influence which units in the downstream storage network of CA3 are recruited (Rolls 1996; McHugh et al. 2007). We anticipate also that future consideration of the advantages of having the DG between EC and CA3 will move beyond the concept of separating two similar inputs toward a greater appreciation of a trade-off between discrimination and generalization, separation of multiple complex patterns, and information transmission (Cerasti and Treves 2010; Barak et al. 2013). To what degree information is stored long-term in the DG remains an essential question because of its implications for how disruptive the addition of new cells would be.

To date, much research focused on the question of how ongoing neurogenesis modifies the DG has looked at how the intrinsic and synaptic physiology of abGCs differs from that of matGCs (see "Bottom-up: characterization of adult-born granule cells"). This bottom-up approach has generated a model in which abGCs for a period of their development ( $\sim 3-6$ wk after birth) are hyperexcitable, less robustly inhibited, and undergo greater synaptic plasticity. The logical implications of these data are that transiently abGCs would be more likely to be activated during behaviors that engage the DG and to undergo (greater) synaptic plasticity. This postulate was given experimental support from population analyses in a slice preparation that found abGCs more likely to be recruited by afferent stimulation (Marín-Burgin et al. 2012).

Most theories of abGC function, therefore, have as their basis the idea that abGCs are preferentially recruited during memory formation. These include abGCs as temporal integrators (Aimone et al. 2006), adult neurogenesis as a means of avoiding catastrophic interference (Wiskott et al. 2006), and the "retirement hypothesis" proposing that matGCs and mature abGCs exit the functional pool of GCs and young abGCs mediate DG function (Alme et al. 2010). In emphasizing the evolution of adult-born neurons' characteristics over time, the temporal integration hypothesis focuses on an important aspect of memory encoding; the ability to recall when events happened and the temporal proximity of events. It is proposed that memories formed closely together will utilize an overlapping population of abGCs that are in their "critical period" (i.e., hyperexcitable/hyperplastic) and this "timestamps" memories through anatomically linking memories in downstream targets (Aimone et al. 2006). Time is clearly an important aspect of memory, and a recent study has shown the DG may play a critical role in encoding temporal relationships (Morris et al. 2013); however, the temporal integration hypothesis has thus far not received empirical support.

The problem faced by all these theories is, however, that few data from behaving mice support the central requirement of abGCs being preferentially (or in some cases solely) recruited during learning. IEG studies suggest that when an animal undergoes an experience, young abGCs are not preferentially activated relative to matGCs (Stone et al. 2011), with IEG induction occurring only in a sparse number of abGCs, even in their critical periods (Kee et al. 2007; Stone et al. 2011; Gu et al. 2012). Moreover, whereas LTP is impaired in slices lacking abGCs in the single in vivo study to date it was unimpaired over a similar timeframe (Kitamura et al. 2009).

Caveats, such as the possibility that activity is more weakly linked to IEG expression in immature abGCs than in matGCs (Kuipers et al. 2009) or that meaningful firing of abGCs and matGCs can occur without IEG induction, are reason to consider these data provisional. However, until another more sensitive in vivo recording technique contradicts these findings, the conclusion that abGCs are no more likely activated by a given experience than matGCs must be taken seriously.

Recordings from awake behaving animals remain a central requirement for developing a theory of DG function in general and of adult neurogenesis specifically; the in vivo firing patterns of neurons are an essential touchstone for theories of any brain region. For the DG they will be essential in revealing not only if abGCs are active at some point in a behavioral task (i.e., what IEG expression reveals) but whether or not their stimulus selectivity, spatial firing profile, or phase-locking to local oscillations differ from those of matGCs.

Results from top-down approaches have, to date, rather than pinpointed a specific cognitive function of abGCs, implicated these cells in an array of mnemonic and affective behaviors (see "Adult hippocampal neurogenesis and its regulation"). Therefore, more work, likely employing refined techniques for silencing and activating these cells, is still needed to refine the list of functions ascribed to abGCs.

Here, we have focused on recent studies that have highlighted abGCs as key contributors to discriminative learning and memory (Clelland et al. 2009; Sahay et al. 2011b; Kheirbek et al. 2012a; 
Tronel et al. 2012). This hypothesis increasingly demands that the mechanisms by which the DG functions in pattern separation during memory encoding are determined; i.e., resolving the current uncertainty over whether expansion of input differences is achieved via rate remapping across the entire GC population (Leutgeb et al. 2007) or via the recruitment of different cohorts of GCs by only marginally different inputs. Furthermore, the suggestion that abGCs alone are sufficient to mediate pattern separation (Nakashiba et al. 2012) would require an entirely novel conceptualization of how this process is achieved. Recent IEG studies allowing labeling of recently and remotely activated cells have produced the interesting result that experiencing the same context (albeit days apart) recruits largely nonoverlapping subpopulations of GCs, suggesting that even identical external cues can lead to the activation of largely nonoverlapping GC cohorts (Tayler et al. 2013; CA Denny, pers. comm.).

The two dominant threads of research, that abGCs are required for pattern separation and that abGCs are hyperresponsive, represent a major challenge for adult neurogenesis research. It is striking that slice physiology experiments led to the conclusion that abGCs are more likely than matGCs to spike in response to both of two distinct inputs (Marín-Burgin et al. 2012). This would appear to be the antithesis of what would be predicted for an element making an essential contribution to a pattern separation circuit.

Resolving this issue will likely require a greater understanding of the network connectivity of abGCs as they develop (Vivar et al. 2012; Deshpande et al. 2013). One possibility is that for a period the abGC population is only sparsely connected to EC and this influences responses to neocortical activity (Deshpande et al. 2013). Conversely, these synaptic tracing studies also demonstrated that abGCs are robustly connected to the local circuitry early in their development.

Although GCs are not synaptically connected to one another and may function autonomously in important ways, the rich network of interneurons in the DG and underlying hilus (including both negative- and positive-feedback loops) indicate that processing of information within the DG is likely complex and that the selection of active GCs is tightly controlled. We are particularly interested in this facet of neurogenesis and believe that a theory of abGC function will not be complete without consideration of each cell's numerous synaptic partners rather than just its EC inputs and its output to CA3 pyramidal neurons (Sahay et al. 2011a).

Lacefield et al. (2012) provided, to date, the only in vivo data exploring the impact of abGCs on DG network activity. This study focused on spontaneously occurring $\gamma$ bursts in the DG of anesthetized mice that lacked abGCs. Following the loss of abGCs these $\gamma$ bursts, which were dependent on entorhinal cortical input, were of larger amplitude, and action potentials occurring within these bursts were more phase-locked to the $\theta$ frequency component.

Network oscillations are emergent phenomena that rely on the interaction of various neuronal types within a network and crucially depend on the synchronized firing of INs (Mann et al. 2005; Bartos et al. 2007; Atallah and Scanziani 2009). $\gamma$ frequency oscillations are predominately mediated by the coherent firing of parvalbumin-expressing basket cells (Gulyás et al. 2010). Hence, these findings strongly implicate abGCs in the local control of IN activity that feeds back onto the entire GC population to control firing (Lacefield et al. 2012). Such observations are consistent with the morphology of DG PV basket cells that receive input from GCs and extend axonal arborizations across large swathes of the GCL (Lübke et al. 1998) and support the hypothesis that abGCs impact activity across the entire DG network (see also Piatti et al. 2013).

Consistently, the result of Burghardt et al. (2012) showing that when abGCs were absent a greater number of matGCs ex- pressed the IEG arc after mice had learned a newly instated rule likewise supports the notion that abGCs regulate activity across the whole GC population. It is interesting to note that the DG has evolved a unique set of GCs, the semilunar cells that appear to regulate hilar mossy cell activity in a way distinct to that of conventional GCs (Larimer and Strowbridge 2010); it may be that abGCs function to regulate local processing in another distinct way.

What advantages might be gained from regulating local circuits, and pattern separation, in a cell-age dependent manner remains an outstanding question. As emphasized in the section "Efferent synaptic connectivity and plasticity" the DG network undergoes significant structural plasticity, in particular in MF connectivity to INs (Ruediger et al. 2011). These processes have not been studied in relation to adult neurogenesis; the possibility exists that dynamic reorganization of connectivity, including incorporation of new neurons, is required for key DG functions including pattern separation where it might facilitate diversifying the cohort of cells recruited by similar experiences occurring at different times.

In sum, there is now strong evidence that neurogenesis contributes to a variety of hippocampal functions, both in the cognitive and in the emotional domain. Moreover, recent data indicate that neurogenesis happens in the human brain at significant levels (similar to middle-aged rodents) through to old age (Spalding

Table 1. Comparison of adult-born granule cell properties with overall properties of the dentate gyrus

\begin{tabular}{|c|c|c|}
\hline & Dentate gyrus & $\begin{array}{l}\text { Adult-born granule } \\
\text { cells }\end{array}$ \\
\hline Cell number & $\begin{array}{l}\text { DG }>\text { entorhinal cortex } \\
\text { DG }>\text { CA3 (Amaral } \\
\text { et al. 1990) }\end{array}$ & $\begin{array}{l}\text { abGCs }<<\text { entorhinal } \\
\text { cortex abGCs }<< \\
\text { CA3 }\end{array}$ \\
\hline Activity levels & $\begin{array}{l}\text { Sparse (Jung and } \\
\text { McNaughton 1993) }\end{array}$ & $\begin{array}{l}\text { Sparse? Less selective? } \\
\text { (Chawla et al. } \\
\text { 2005) }\end{array}$ \\
\hline $\begin{array}{l}\text { Mnemonic spatial } \\
\text { and contextual } \\
\text { discrimination }\end{array}$ & $\begin{array}{l}\text { Significant data } \\
\text { supports crucial role } \\
\text { (see Hunsaker and } \\
\text { Kesner 2013) }\end{array}$ & $\begin{array}{l}\text { Accumulating data } \\
\text { supports crucial role } \\
\text { (Clelland et al. } \\
\text { 2009; Sahay et al. } \\
2011 \text {; Kheirbek } \\
\text { et al. 2012a; Niibori } \\
\text { et al. 2012) }\end{array}$ \\
\hline $\begin{array}{l}\text { Mechanism of } \\
\text { pattern } \\
\text { separation }\end{array}$ & $\begin{array}{l}\text { Expansion coding } \\
\text { involving a rate code } \\
\text { (Leutgeb et al. 2007) } \\
\text { and/or recruitment of } \\
\text { distinct sets of cells } \\
\text { (Rolls 1996; Rolls and } \\
\text { Kesner 2006; Tayler } \\
\text { et al. 2013)? }\end{array}$ & Unknown \\
\hline Contextual learning & $\begin{array}{l}\text { Evidence for encoding } \\
\text { function but not } \\
\text { recall (Kheirbek et al. } \\
\text { 2013) }\end{array}$ & $\begin{array}{l}\text { Key role for rapid } \\
\text { encoding of } \\
\text { contextual } \\
\text { information? (Drew } \\
\text { et al. 2010) }\end{array}$ \\
\hline Stress response & $\begin{array}{l}\text { High expression of } \\
\text { stress hormone } \\
\text { receptors- } \\
\text { hippocampus can } \\
\text { regulate HPA axis }\end{array}$ & $\begin{array}{l}\text { May modulate stress } \\
\text { response by } \\
\text { interacting with } \\
\text { HPA axis } \\
\text { (Schloesser et al. } \\
2009 ; \text { Snyder et al. } \\
2011)^{1}\end{array}$ \\
\hline $\begin{array}{l}\text { Antidepressant } \\
\text { response }\end{array}$ & $\begin{array}{l}\text { Antidepressants may } \\
\text { globally increase } \\
\text { activity (Airan et al. } \\
\text { 2007)—-mechanism } \\
\text { uncertain }\end{array}$ & $\begin{array}{l}\text { Neurogenesis } \\
\text { required for } \\
\text { behavioral response } \\
\text { to SSRIs in some } \\
\text { tests (Santarelli } \\
\text { et al. 2003)- } \\
\text { mechanism } \\
\text { uncertain }\end{array}$ \\
\hline
\end{tabular}


et al. 2013), supporting the hypothesis that it is functionally relevant in people.

Why the DG is one of only two areas of the mammalian brain where significant adult neurogenesis occurs remains an open question. Here, we have considered various physiological and functional features of the DG which may be important for this question. That adult hippocampal neurogenesis exists and the fact that it is regulated by environmental factors and hippocampal activity argue that it allows the organism to better respond to the variations in cognitive and affective demands that result from a changing environment. Recent studies highlight the dynamic nature of DG contributions to mnemonic functioning and the interaction between memory encoding, storage, and retrieval processes. A greater understanding of network function in the hippocampus, where memories are only stored transiently, will likely improve our understanding of why it alone may particularly benefit from this phenomenon.

\section{Acknowledgments}

We thank Helen Scharfman for discussion and Mazen Kheirbek and Gregg Crabtree for comments on this manuscript. The Hen lab is supported by the New York Stem Cell Initiative (NYSTEM C026430), NIH R37 MH068542, and Hope for Depression Research Foundation grants. Additionally, L.J.D. is the recipient of a Kavli Institute Post-Doctoral Fellowship. The Fusi lab is supported by Gatsby, Swartz, and Kavli Foundations. R.H. receives compensation as a consultant for Lundbeck and Roche.

\section{References}

Acsády L, Kamondi A, Sík A, Freund T, Buzsáki G. 1998. GABAergic cells are the major postsynaptic targets of mossy fibers in the rat hippocampus. J Neurosci 18: 3386-3403.

Adams B, Lee M, Fahnestock M, Racine RJ. 1997. Long-term potentiation trains induce mossy fiber sprouting. Brain Res 775: 193-197.

Adhikari A, Topiwala MA, Gordon JA. 2011. Single units in the medial prefrontal cortex with anxiety-related firing patterns are preferentially influenced by ventral hippocampal activity. Neuron 71: $898-910$.

Aimone JB, Wiles J, Gage FH. 2006. Potential role for adult neurogenesis in the encoding of time in new memories. Nat Neurosci 9: 723-727.

Airan RD, Meltzer LA, Roy M, Gong Y, Chen H, Deisseroth K. 2007. High-speed imaging reveals neurophysiological links to behavior in an animal model of depression. Science 317: 819-823.

Alme CB, Buzzetti RA, Marrone DF, Leutgeb JK, Chawla MK, Schaner MJ, Bohanick JD, Khoboko T, Leutgeb S, Moser EI, et al. 2010. Hippocampal granule cells opt for early retirement. Hippocampus 20: 1109-1123.

Amaral DG, Ishizuka N, Claiborne B. 1990. Neurons, numbers and the hippocampal network. Prog Brain Res 83: 1-11.

Amaral DG, Scharfman HE, Lavenex P. 2007. The dentate gyrus: Fundamental neuroanatomical organization (dentate gyrus for dummies). Prog Brain Res 163: 3-22.

Amrein I, Dechmann DK, Winter Y, Lipp HP. 2007. Absent or low rate of adult neurogenesis in the hippocampus of bats (Chiroptera). PLoS One 2: e455.

Amrein I, Isler K, Lipp HP. 2011. Comparing adult hippocampal neurogenesis in mammalian species and orders: Influence of chronological age and life history stage. Eur J Neurosci 34: 978-987.

Arruda-Carvalho M, Sakaguchi M, Akers KG, Josselyn SA, Frankland PW. 2011. Posttraining ablation of adult-generated neurons degrades previously acquired memories. J Neurosci 31: 15113-15127.

Atallah BV, Scanziani M. 2009. Instantaneous modulation of $\gamma$ oscillation frequency by balancing excitation with inhibition. Neuron 62: $566-577$.

Barak O, Rigotti M, Fusi S. 2013. The sparseness of mixed selectivity neurons controls the generalization-discrimination trade-off. J Neurosci 33: $3844-3856$.

Barker JM, Boonstra R, Wojtowicz JM. 2011. From pattern to purpose: How comparative studies contribute to understanding the function of adult neurogenesis. Eur J Neurosci 34: 963-977.

Barnes SJ, Opitz T, Merkens M, Kelly T, von der Brelie C, Krueppel R, Beck H. 2010. Stable mossy fiber long-term potentiation requires calcium influx at the granule cell soma, protein synthesis, and microtubule-dependent axonal transport. J Neurosci 30: 12996-13004.
Bartos M, Vida I, Jonas P. 2007. Synaptic mechanisms of synchronized $\gamma$ oscillations in inhibitory interneuron networks. Nat Rev Neurosci 8: $45-56$.

Becker S, Wojtowicz JM. 2007. A model of hippocampal neurogenesis in memory and mood disorders. Trends Cogn Sci 11: 70-76.

Bliss TV, Lomo T. 1973. Long-lasting potentiation of synaptic transmission in the dentate area of the anaesthetized rabbit following stimulation of the perforant path. J Physiol 232: 331-356.

Boldrini M, Underwood MD, Hen R, Rosoklija GB, Dwork AJ, Mann JJ, Arango V. 2009. Antidepressants increase neural progenitor cells in the human hippocampus. Neuropsychopharmacology 34: 2376-2389.

Boldrini M, Hen R, Underwood MD, Rosoklija GB, Dwork AJ, Mann JJ, Arango V. 2012. Hippocampal angiogenesis and progenitor cell proliferation are increased with antidepressant use in major depression. Biol Psychiatry 72: 562-571.

Bolshakov VY, Siegelbaum SA. 1995. Regulation of hippocampal transmitter release during development and long-term potentiation. Science 269: 1730-1734.

Bonaguidi MA, Wheeler MA, Shapiro JS, Stadel RP, Sun GJ, Ming GL, Song H. 2011. In vivo clonal analysis reveals self-renewing and multipotent adult neural stem cell characteristics. Cell 145: 1142-1155.

Buhl E, Whittington M. 2007. Local circuits. In The hippocampus book (ed. Andersen P, Moris R, Amaral D, Bliss T, O'Keefe J), pp. 297-320. Oxford University Press, New York.

Burghardt NS, Park EH, Hen R, Fenton AA. 2012. Adult-born hippocampal neurons promote cognitive flexibility in mice. Hippocampus 22: 1795-1808.

Bush TG, Savidge TC, Freeman TC, Cox HJ, Campbell EA, Mucke L, Johnson MH, Sofroniew MV. 1998. Fulminant jejuno-ileitis following ablation of enteric glia in adult transgenic mice. Cell 93: 189-201.

Buzsáki G, Moser EI. 2013. Memory, navigation and $\theta$ rhythm in the hippocampal-entorhinal system. Nat Neurosci 16: 130-138.

Cavegn N, van Dijk RM, Menges D, Brettschneider H, Phalanndwa M, Chimimba CT, Isler K, Lipp HP, Slomianka L, Amrein I. 2013. Habitatspecific shaping of proliferation and neuronal differentiation in adult hippocampal neurogenesis of wild rodents. Front Neurosci 7: 59.

Cerasti E, Treves A. 2010. How informative are spatial CA3 representations established by the dentate gyrus? PLoS Comput Biol 6: e1000759.

Chawla MK, Guzowski JF, Ramirez-Amaya V, Lipa P, Hoffman KL, Marriott LK, Worley PF, McNaughton BL, Barnes CA. 2005. Sparse, environmentally selective expression of Arc RNA in the upper blade of the rodent fascia dentata by brief spatial experience. Hippocampus 15: $579-586$

Chiang PH, Wu PY, Kuo TW, Liu YC, Chan CF, Chien TC, Cheng JK, Huang YY, Chiu CD, Lien CC. 2012. GABA is depolarizing in hippocampal dentate granule cells of the adolescent and adult rats. J Neurosci 32: 62-67.

Christian K, Song H, Ming GL. 2010. Adult neurogenesis as a cellular model to study schizophrenia. Cell Cycle 9: 636-637.

Clelland CD, Choi M, Romberg C, Clemenson GD Jr., Fragniere A, Tyers P, Jessberger S, Saksida LM, Barker RA, Gage FH, et al. 2009. A functional role for adult hippocampal neurogenesis in spatial pattern separation. Science 325: 210-213.

Coulter DA, Carlson GC. 2007. Functional regulation of the dentate gyrus by GABA-mediated inhibition. Prog Brain Res 163: 235-243.

Creer DJ, Romberg C, Saksida LM, van Praag H, Bussey TJ. 2010. Running enhances spatial pattern separation in mice. Proc Natl Acad Sci 107: 2367-2372.

David DJ, Samuels BA, Rainer Q, Wang JW, Marsteller D, Mendez I, Drew M, Craig DA, Guiard BP, Guilloux JP, et al. 2009. Neurogenesis-dependent and -independent effects of fluoxetine in an animal model of anxiety/ depression. Neuron 62: 479-493.

de Almeida L, Idiart M, Lisman JE. 2009. The input-output transformation of the hippocampal granule cells: From grid cells to place fields. $J$ Neurosci 29: 7504-7512.

Deng W, Aimone JB, Gage FH. 2010. New neurons and new memories: How does adult hippocampal neurogenesis affect learning and memory? Nat Rev Neurosci 11: 339-350.

Denny CA, Burghardt NS, Schachter DM, Hen R, Drew MR. 2012. 4- to 6-week-old adult-born hippocampal neurons influence novelty-evoked exploration and contextual fear conditioning. Hippocampus 22: $1188-1201$.

Deshpande A, Bergami M, Ghanem A, Conzelmann KK, Lepier A, Götz M, Berninger B. 2013. Retrograde monosynaptic tracing reveals the temporal evolution of inputs onto new neurons in the adult dentate gyrus and olfactory bulb. Proc Natl Acad Sci 110: E1152-E1161.

Dombeck DA, Harvey CD, Tian L, Looger LL, Tank DW. 2010. Functional imaging of hippocampal place cells at cellular resolution during virtual navigation. Nat Neurosci 13: 1433-1440.

Dranovsky A, Leonardo ED. 2012. Is there a role for young hippocampal neurons in adaptation to stress? Behav Brain Res 227: 371-375. 
Dranovsky A, Picchini AM, Moadel T, Sisti AC, Yamada A, Kimura S, Leonardo ED, Hen R. 2011. Experience dictates stem cell fate in the adult hippocampus. Neuron 70: 908-923.

Drew MR, Denny CA, Hen R. 2010. Arrest of adult hippocampal neurogenesis in mice impairs single- but not multiple-trial contextual fear conditioning. Behav Neurosci 124: 446-454.

Drew LJ, Stark KL, Fénelon K, Karayiorgou M, Macdermott AB, Gogos JA. 2011. Evidence for altered hippocampal function in a mouse model of the human 22q11.2 microdeletion. Mol Cell Neurosci 47: 293-305.

Duan X, Chang JH, Ge S, Faulkner RL, Kim JY, Kitabatake Y, Liu XB, Yang CH, Jordan JD, Ma DK, et al. 2007. Disrupted-In-Schizophrenia 1 regulates integration of newly generated neurons in the adult brain. Cell 130: $1146-1158$.

Dupret D, Fabre A, Döbrössy MD, Panatier A, Rodríguez JJ, Lamarque S, Lemaire V, Oliet SH, Piazza PV, Abrous DN. 2007. Spatial learning depends on both the addition and removal of new hippocampal neurons. PLoS Biol 5: e214.

Dupret D, Revest JM, Koehl M, Ichas F, De Giorgi F, Costet P, Abrous DN, Piazza PV. 2008. Spatial relational memory requires hippocampal adult neurogenesis. PLoS One 3: e1959.

Eisch AJ, Barrot M, Schad CA, Self DW, Nestler EJ. 2000. Opiates inhibit neurogenesis in the adult rat hippocampus. Proc Natl Acad Sci 97: 7579-7584.

Epsztein J, Brecht M, Lee AK. 2011. Intracellular determinants of hippocampal CA1 place and silent cell activity in a novel environment. Neuron 70: 109-120.

Eriksson PS, Perfilieva E, Björk-Eriksson T, Alborn AM, Nordborg C, Peterson DA, Gage FH. 1998. Neurogenesis in the adult human hippocampus. Nat Med 4: 1313-1317.

Espósito MS, Piatti VC, Laplagne DA, Morgenstern NA, Ferrari CC, Pitossi FJ, Schinder AF. 2005. Neuronal differentiation in the adult hippocampus recapitulates embryonic development. J Neurosci 25: 10074-10086.

Ewell LA, Jones MV. 2010. Frequency-tuned distribution of inhibition in the dentate gyrus. J Neurosci 30: 12597-12607.

Faigle R, Song H. 2013. Signaling mechanisms regulating adult neural stem cells and neurogenesis. Biochim Biophys Acta 1830: 2435-2448.

Fanselow MS, Dong HW. 2010. Are the dorsal and ventral hippocampus functionally distinct structures? Neuron 65: 7-19.

Faulkner RL, Jang MH, Liu XB, Duan X, Sailor KA, Kim JY, Ge S, Jones EG, Ming GL, Song H, et al. 2008. Development of hippocampal mossy fiber synaptic outputs by new neurons in the adult brain. Proc Natl Acad Sci 105: $14157-14162$

Ford EC, Achanta P, Purger D, Armour M, Reyes J, Fong J, Kleinberg L, Redmond K, Wong J, Jang MH, et al. 2011. Localized CT-guided irradiation inhibits neurogenesis in specific regions of the adult mouse brain. Radiat Res 175: 774-783.

Fowler CD, Liu Y, Ouimet C, Wang Z. 2002. The effects of social environment on adult neurogenesis in the female prairie vole. J Neurobiol 51: 115-128.

Frankland PW, Cestari V, Filipkowski RK, McDonald RJ, Silva AJ. 1998. The dorsal hippocampus is essential for context discrimination but not for contextual conditioning. Behav Neurosci 112: 863-874.

Frankland PW, Köhler S, Josselyn SA. 2013. Hippocampal neurogenesis and forgetting. Trends Neurosci 36: 497-503.

Friedman SD. 2008. Comment on "Magnetic resonance spectroscopy identifies neural progenitor cells in the live human brain". Science 321: 640 .

Fusi S, Drew PJ, Abbott LF. 2005. Cascade models of synaptically stored memories. Neuron 45: 599-611.

Galimberti I, Gogolla N, Alberi S, Santos AF, Muller D, Caroni P. 2006. Long-term rearrangements of hippocampal mossy fiber terminal connectivity in the adult regulated by experience. Neuron 50: 749-763.

Galvan V, Bredesen DE. 2007. Neurogenesis in the adult brain: Implications for Alzheimer's disease. CNS Neurol Disord Drug Targets 6: 303-310.

Garthe A, Behr J, Kempermann G. 2009. Adult-generated hippocampal neurons allow the flexible use of spatially precise learning strategies. PLoS One 4: e5464.

Ge S, Goh EL, Sailor KA, Kitabatake Y, Ming GL, Song H. 2006. GABA regulates synaptic integration of newly generated neurons in the adult brain. Nature 439: 589-593

Ge S, Yang CH, Hsu KS, Ming GL, Song H. 2007. A critical period for enhanced synaptic plasticity in newly generated neurons of the adult brain. Neuron 54: 559-566.

Ge S, Sailor KA, Ming GL, Song H. 2008. Synaptic integration and plasticity of new neurons in the adult hippocampus. J Physiol 586: 3759-3765.

Geiger JR, Lübke J, Roth A, Frotscher M, Jonas P. 1997. Submillisecond AMPA receptor-mediated signaling at a principal neuron-interneuron synapse. Neuron 18: 1009-1023.

Gilbert PE, Kesner RP, Lee I. 2001. Dissociating hippocampal subregions: Double dissociation between dentate gyrus and CA1. Hippocampus 11: 626-636.
Gould E, Cameron HA, Daniels DC, Woolley CS, McEwen BS. 1992. Adrenal hormones suppress cell division in the adult rat dentate gyrus. J Neurosci 12: $3642-3650$.

Gould E, McEwen BS, Tanapat P, Galea LA, Fuchs E. 1997. Neurogenesis in the dentate gyrus of the adult tree shrew is regulated by psychosocial stress and NMDA receptor activation. J Neurosci 17: 2492-2498.

Grabiec M, Turlejski K, Djavadian RL. 2009. The partial 5-HT1A receptor agonist buspirone enhances neurogenesis in the opossum (Monodelphis domestica). Eur Neuropsychopharmacol 19: 431-439.

Gross CG. 2000. Neurogenesis in the adult brain: Death of a dogma. Nat Rev Neurosci 1: $67-73$

Gu Y, Arruda-Carvalho M, Wang J, Janoschka SR, Josselyn SA, Frankland PW, Ge S. 2012. Optical controlling reveals time-dependent roles for adult-born dentate granule cells. Nat Neurosci 15: 1700-1706.

Gulyás AI, Szabó GG, Ulbert I, Holderith N, Monyer H, Erdélyi F, Szabó G, Freund TF, Hájos N. 2010. Parvalbumin-containing fast-spiking basket cells generate the field potential oscillations induced by cholinergic receptor activation in the hippocampus. J Neurosci 30: 15134-15145.

Gundlfinger A, Breustedt J, Sullivan D, Schmitz D. 2010. Natural spike trains trigger short- and long-lasting dynamics at hippocampal mossy fiber synapses in rodents. PLoS One 5: e9961.

Guo W, Allan AM, Zong R, Zhang L, Johnson EB, Schaller EG, Murthy AC, Goggin SL, Eisch AJ, Oostra BA, et al. 2011. Ablation of Fmrp in adult neural stem cells disrupts hippocampus-dependent learning. Nat Med 17: $559-565$

Guzowski JF, Timlin JA, Roysam B, McNaughton BL, Worley PF, Barnes CA. 2005. Mapping behaviorally relevant neural circuits with immediate-early gene expression. Curr Opin Neurobiol 15: 599-606.

Hargreaves EL, Rao G, Lee I, Knierim JJ. 2005. Major dissociation between medial and lateral entorhinal input to dorsal hippocampus. Science 308: $1792-1794$

Harman A, Meyer P, Ahmat A. 2003. Neurogenesis in the hippocampus of an adult marsupial. Brain Behav Evol 62: 1-12.

Harris EW, Cotman CW. 1986. Long-term potentiation of guinea pig mossy fiber responses is not blocked by $N$-methyl-D-aspartate antagonists. Neurosci Lett 70: 132-137.

Hefft S, Jonas P. 2005. Asynchronous GABA release generates long-lasting inhibition at a hippocampal interneuron-principal neuron synapse. Nat Neurosci 8: 1319-1328.

Henze DA, Urban NN, Barrionuevo G. 2000. The multifarious hippocampal mossy fiber pathway: A review. Neuroscience 98: 407-427.

Henze DA, Wittner L, Buzsáki G. 2002. Single granule cells reliably discharge targets in the hippocampal CA3 network in vivo. Nat Neurosci 5: $790-795$.

Hoch JC, Maciejewski MW, Gryk MR. 2008. Comment on "Magnetic resonance spectroscopy identifies neural progenitor cells in the live human brain". Science 321: 640.

Houser CR. 2007. Interneurons of the dentate gyrus: An overview of cell types, terminal fields and neurochemical identity. Prog Brain Res 163: $217-232$.

Hunsaker MR, Kesner RP. 2013. The operation of pattern separation and pattern completion processes associated with different attributes or domains of memory. Neurosci Biobehav Rev 37: 36-58.

Hunsaker MR, Rosenberg JS, Kesner RP. 2008. The role of the dentate gyrus, CA3a,b, and CA3c for detecting spatial and environmental novelty. Hippocampus 18: $1064-1073$.

Ide Y, Fujiyama F, Okamoto-Furuta K, Tamamaki N, Kaneko T, Hisatsune T. 2008. Rapid integration of young newborn dentate gyrus granule cells in the adult hippocampal circuitry. Eur J Neurosci 28: 2381-2392.

Imayoshi I, Sakamoto M, Ohtsuka T, Takao K, Miyakawa T, Yamaguchi M, Mori K, Ikeda T, Itohara S, Kageyama R. 2008. Roles of continuous neurogenesis in the structural and functional integrity of the adult forebrain. Nat Neurosci 11: 1153-1161.

Jansen JF, Gearhart JD, Bulte JW. 2008. Comment on "Magnetic resonance spectroscopy identifies neural progenitor cells in the live human brain". Science 321: 640.

Jinde S, Zsiros V, Jiang Z, Nakao K, Pickel J, Kohno K, Belforte JE, Nakazawa K. 2012. Hilar mossy cell degeneration causes transient dentate granule cell hyperexcitability and impaired pattern separation. Neuron 76: $1189-1200$

Josselyn SA, Frankland PW. 2012. Infantile amnesia: A neurogenic hypothesis. Learn Mem 19: 423-433.

Jung MW, McNaughton BL. 1993. Spatial selectivity of unit activity in the hippocampal granular layer. Hippocampus 3: 165-182.

Kaelin WG Jr. 2012. Molecular biology. Use and abuse of RNAi to study mammalian gene function. Science 337: 421-422.

Kaslin J, Ganz J, Brand M. 2008. Proliferation, neurogenesis and regeneration in the non-mammalian vertebrate brain. Philos Trans $R$ Soc Lond B Biol Sci 363: 101-122.

Kee N, Teixeira CM, Wang AH, Frankland PW. 2007. Preferential incorporation of adult-generated granule cells into spatial memory networks in the dentate gyrus. Nat Neurosci 10: 355-362. 
Kempermann G. 2012. New neurons for 'survival of the fittest'. Nat Rev Neurosci 13: 727-736.

Kempermann G, Kuhn HG, Gage FH. 1997. More hippocampal neurons in adult mice living in an enriched environment. Nature 386: 493-495.

Kerr AM, Jonas P. 2008. The two sides of hippocampal mossy fiber plasticity. Neuron 57: 5-7.

Kesner RP. 2007. A behavioral analysis of dentate gyrus function. Prog Brain Res 163: $567-576$.

Kesner RP. 2013. An analysis of the dentate gyrus function. Behav Brain Res 254: $1-7$.

Kesner RP, Hunsaker MR, Ziegler W. 2011. The role of the dorsal and ventral hippocampus in olfactory working memory. Neurobiol Learn Mem 96: 361-366.

Kheirbek MA, Hen R. 2011. Dorsal vs ventral hippocampal neurogenesis: Implications for cognition and mood. Neuropsychopharmacology 36: 373-374.

Kheirbek MA, Tannenholz L, Hen R. 2012a. NR2B-dependent plasticity of adult-born granule cells is necessary for context discrimination. $J$ Neurosci 32: 8696-8702.

Kheirbek MA, Klemenhagen KC, Sahay A, Hen R. 2012b. Neurogenesis and generalization: A new approach to stratify and treat anxiety disorders. Nat Neurosci 15: 1613-1620.

Kheirbek MA, Drew LJ, Burghardt NS, Costantini DO, Tannenholz L, Ahmari SE, Zeng H, Fenton AA, Hen R. 2013. Differential control of learning and anxiety along the dorsoventral axis of the dentate gyrus. Neuron 77: 955-968.

Kitamura T, Saitoh Y, Takashima N, Murayama A, Niibori Y, Ageta H, Sekiguchi M, Sugiyama H, Inokuchi K. 2009. Adult neurogenesis modulates the hippocampus-dependent period of associative fear memory. Cell 139: 814-827.

Knoth R, Singec I, Ditter M, Pantazis G, Capetian P, Meyer RP, Horvat V, Volk B, Kempermann G. 2010. Murine features of neurogenesis in the human hippocampus across the lifespan from 0 to 100 years. PLoS One 5: e8809.

Kobayashi K, Poo MM. 2004. Spike train timing-dependent associative modification of hippocampal CA3 recurrent synapses by mossy fibers. Neuron 41: $445-454$.

Koehl M, Abrous DN. 2011. A new chapter in the field of memory: Adult hippocampal neurogenesis. Eur J Neurosci 33: 1101-1114.

Kohler SJ, Williams NI, Stanton GB, Cameron JL, Greenough WT. 2011. Maturation time of new granule cells in the dentate gyrus of adult macaque monkeys exceeds six months. Proc Natl Acad Sci 108: 10326-10331.

Kornack DR, Rakic P. 1999. Continuation of neurogenesis in the hippocampus of the adult macaque monkey. Proc Natl Acad Sci 96: 5768-5773.

Krueppel R, Remy S, Beck H. 2011. Dendritic integration in hippocampal dentate granule cells. Neuron 71: 512-528.

Kuipers SD, Tiron A, Soule J, Messaoudi E, Trentani A, Bramham CR. 2009 Selective survival and maturation of adult-born dentate granule cells expressing the immediate early gene Arc/Arg3.1. PLoS One 4: e4885.

Kumamoto N, Gu Y, Wang J, Janoschka S, Takemaru K, Levine J, Ge S. 2012. A role for primary cilia in glutamatergic synaptic integration of adult-born neurons. Nat Neurosci 15: 399-405.

Kvajo M, McKellar H, Arguello PA, Drew LJ, Moore H, MacDermott AB, Karayiorgou M, Gogos JA. 2008. A mutation in mouse Disc1 that models a schizophrenia risk allele leads to specific alterations in neuronal architecture and cognition. Proc Natl Acad Sci 105: 7076-7081.

Kvajo M, McKellar H, Drew LJ, Lepagnol-Bestel AM, Xiao L, Levy RJ, Blazeski R, Arguello PA, Lacefield CO, Mason CA, et al. 2011. Altered axonal targeting and short-term plasticity in the hippocampus of Disc1 mutant mice. Proc Natl Acad Sci 108: E1349-E1358.

Lacefield CO, Itskov V, Reardon T, Hen R, Gordon JA. 2012. Effects of adult-generated granule cells on coordinated network activity in the dentate gyrus. Hippocampus 22: 106-116.

Laplagne DA, Espósito MS, Piatti VC, Morgenstern NA, Zhao C, van Praag H, Gage FH, Schinder AF. 2006. Functional convergence of neurons generated in the developing and adult hippocampus. PLoS Biol 4: e409.

Larimer P, Strowbridge BW. 2010. Representing information in cell assemblies: Persistent activity mediated by semilunar granule cells. Nat Neurosci 13: 213-222.

Lawrence JJ, McBain CJ. 2003. Interneuron diversity series: Containing the detonation-feedforward inhibition in the CA3 hippocampus. Trends Neurosci 26: 631-640.

Lemaire V, Tronel S, Montaron MF, Fabre A, Dugast E, Abrous DN. 2012. Long-lasting plasticity of hippocampal adult-born neurons. J Neurosci 32: $3101-3108$

Leutgeb JK, Leutgeb S, Moser MB, Moser EI. 2007. Pattern separation in the dentate gyrus and CA3 of the hippocampus. Science 315: 961-966.
Li Y, Aimone JB, Xu X, Callaway EM, Gage FH. 2012. Development of GABAergic inputs controls the contribution of maturing neurons to the adult hippocampal network. Proc Natl Acad Sci 109: 4290-4295.

Lindsey BW, Tropepe V. 2006. A comparative framework for understanding the biological principles of adult neurogenesis. Prog Neurobiol 80: $281-307$.

Lisman J. 2011. Formation of the non-functional and functional pools of granule cells in the dentate gyrus: Role of neurogenesis, LTP and LTD. J Physiol 589: 1905-1909.

Liu YB, Lio PA, Pasternak JF, Trommer BL. 1996. Developmental changes in membrane properties and postsynaptic currents of granule cells in rat dentate gyrus. J Neurophysiol 76: 1074-1088.

Liu X, Ramirez S, Pang PT, Puryear CB, Govindarajan A, Deisseroth K, Tonegawa S. 2012. Optogenetic stimulation of a hippocampal engram activates fear memory recall. Nature 484: 381-385.

Lledo PM, Alonso M, Grubb MS. 2006. Adult neurogenesis and functional plasticity in neuronal circuits. Nat Rev Neurosci 7: 179-193.

Lovett-Barron M, Turi GF, Kaifosh P, Lee PH, Bolze F, Sun XH, Nicoud JF, Zemelman BV, Sternson SM, Losonczy A. 2012. Regulation of neuronal input transformations by tunable dendritic inhibition. Nat Neurosci 15: $423-430$

Lübke J, Frotscher M, Spruston N. 1998. Specialized electrophysiological properties of anatomically identified neurons in the hilar region of the rat fascia dentata. J Neurophysiol 79: 1518-1534.

MacMillan KS, Naidoo J, Liang J, Melito L, Williams NS, Morlock L, Huntington PJ, Estill SJ, Longgood J, Becker GL, et al. 2011. Development of proneurogenic, neuroprotective small molecules. J Am Chem Soc 133: 1428-1437.

Malberg JE, Eisch AJ, Nestler EJ, Duman RS. 2000. Chronic antidepressant treatment increases neurogenesis in adult rat hippocampus. J Neurosci 20: $9104-9110$.

Mandyam CD, Koob GF. 2012. The addicted brain craves new neurons: Putative role for adult-born progenitors in promoting recovery. Trends Neurosci 35: 250-260.

Manganas LN, Zhang X, Li Y, Hazel RD, Smith SD, Wagshul ME, Henn F, Benveniste H, Djuric PM, Enikolopov G, et al. 2007. Magnetic resonance spectroscopy identifies neural progenitor cells in the live human brain. Science 318: 980-985.

Mann EO, Radcliffe CA, Paulsen O. 2005. Hippocampal $\gamma$-frequency oscillations: From interneurones to pyramidal cells, and back. J Physiol 562: $55-63$.

Marín-Burgin A, Schinder AF. 2012. Requirement of adult-born neurons for hippocampus-dependent learning. Behav Brain Res 227: 391-399.

Marín-Burgin A, Mongiat LA, Pardi MB, Schinder AF. 2012. Unique processing during a period of high excitation/inhibition balance in adult-born neurons. Science 335: 1238-1242.

Markwardt SJ, Dieni CV, Wadiche JI, Overstreet-Wadiche L. 2011. Ivy/ neurogliaform interneurons coordinate activity in the neurogenic niche. Nat Neurosci 14: 1407-1409.

Marr D. 1971. Simple memory: A theory for archicortex. Philos Trans R Soc Lond B Biol Sci 262: 23-81.

Massa F, Koehl M, Wiesner T, Grosjean N, Revest JM, Piazza PV, Abrous DN, Oliet SH. 2011. Conditional reduction of adult neurogenesis impairs bidirectional hippocampal synaptic plasticity. Proc Natl Acad Sci 108: 6644-6649.

McGonigal R, Tabatadze N, Routtenberg A. 2012. Selective presynaptic terminal remodeling induced by spatial, but not cued, learning: A quantitative confocal study. Hippocampus 22: 1242-1255.

McHugh TJ, Jones MW, Quinn JJ, Balthasar N, Coppari R, Elmquist JK, Lowell BB, Fanselow MS, Wilson MA, Tonegawa S. 2007. Dentate gyrus NMDA receptors mediate rapid pattern separation in the hippocampal network. Science 317: 94-99.

Meshi D, Drew MR, Saxe M, Ansorge MS, David D, Santarelli L, Malapani C, Moore H, Hen R. 2006. Hippocampal neurogenesis is not required for behavioral effects of environmental enrichment. Nat Neurosci 9: $729-731$.

Ming GL, Song H. 2011. Adult neurogenesis in the mammalian brain: Significant answers and significant questions. Neuron 70: 687-702.

Mirescu C, Gould E. 2006. Stress and adult neurogenesis. Hippocampus 16: $233-238$

Mongiat LA, Espósito MS, Lombardi G, Schinder AF. 2009. Reliable activation of immature neurons in the adult hippocampus. PLoS One 4: e5320.

Monje ML, Mizumatsu S, Fike JR, Palmer TD. 2002. Irradiation induces neural precursor-cell dysfunction. Nat Med 8: 955-962.

Mori-Kawakami F, Kobayashi K, Takahashi T. 2003. Developmental decrease in synaptic facilitation at the mouse hippocampal mossy fibre synapse. J Physiol 553: $37-48$.

Morris AM, Curtis BJ, Churchwell JC, Maasberg DW, Kesner RP. 2013. Temporal associations for spatial events: The role of the dentate gyrus. Behav Brain Res. 256: 250-256. 
Mu Y, Gage FH. 2011. Adult hippocampal neurogenesis and its role in Alzheimer's disease. Mol Neurodegener 6: 85 .

Myers CE, Scharfman HE. 2011. Pattern separation in the dentate gyrus: A role for the CA3 backprojection. Hippocampus 21: 1190-1215.

Nadler JV. 2003. The recurrent mossy fiber pathway of the epileptic brain. Neurochem Res 28: 1649-1658.

Nakashiba T, Cushman JD, Pelkey KA, Renaudineau S, Buhl DL, McHugh TJ, Rodriguez Barrera V, Chittajallu R, Iwamoto KS, McBain CJ, et al. 2012. Young dentate granule cells mediate pattern separation, whereas old granule cells facilitate pattern completion. Cell 149: $188-201$.

Nakazawa K, Quirk MC, Chitwood RA, Watanabe M, Yeckel MF, Sun LD, Kato A, Carr CA, Johnston D, Wilson MA, et al. 2002. Requirement for hippocampal CA3 NMDA receptors in associative memory recall. Science 297: 211-218.

Neunuebel JP, Knierim JJ. 2012. Spatial firing correlates of physiologically distinct cell types of the rat dentate gyrus. J Neurosci 32: 3848-3858.

Nicoll RA, Schmitz D. 2005. Synaptic plasticity at hippocampal mossy fibre synapses. Nat Rev Neurosci 6: 863-876.

Niibori Y, Yu TS, Epp JR, Akers KG, Josselyn SA, Frankland PW. 2012. Suppression of adult neurogenesis impairs population coding of similar contexts in hippocampal CA3 region. Nat Commun 3: 1253.

Nottebohm F. 2004. The road we travelled: Discovery, choreography, and significance of brain replaceable neurons. Ann N Y Acad Sci 1016: $628-658$.

O'Keefe J, Nadel L. 1978. The hippocampus as a cognitive map. Clarendon, Oxford, UK.

O’Reilly RC, McClelland JL. 1994. Hippocampal conjunctive encoding, storage, and recall: Avoiding a trade-off. Hippocampus 4: 661-682.

Overstreet LS, Hentges ST, Bumaschny VF, de Souza FS, Smart JL, Santangelo AM, Low MJ, Westbrook GL, Rubinstein M. 2004. A transgenic marker for newly born granule cells in dentate gyrus. J Neurosci 24: 3251-3259.

Overstreet-Wadiche L, Bromberg DA, Bensen AL, Westbrook GL. 2005. GABAergic signaling to newborn neurons in dentate gyrus. J Neurophysiol 94: 4528-4532.

Overstreet-Wadiche LS, Bensen AL, Westbrook GL. 2006. Delayed development of adult-generated granule cells in dentate gyrus. J Neurosci 26: 2326-2334.

Parent JM, Yu TW, Leibowitz RT, Geschwind DH, Sloviter RS, Lowenstein DH. 1997. Dentate granule cell neurogenesis is increased by seizures and contributes to aberrant network reorganization in the adult rat hippocampus. J Neurosci 17: 2727-3738.

Parent JM, Tada E, Fike JR, Lowenstein DH. 1999. Inhibition of dentate granule cell neurogenesis with brain irradiation does not prevent seizure-induced mossy fiber synaptic reorganization in the rat. J Neurosci 19: 4508-4519.

Peissner W, Kocher M, Treuer H, Gillardon F. 1999. Ionizing radiation-induced apoptosis of proliferating stem cells in the dentate gyrus of the adult rat hippocampus. Brain Res Mol Brain Res 71: $61-68$.

Penttonen M, Kamondi A, Sik A, Acsády L, Buzsáki G. 1997. Feed-forward and feed-back activation of the dentate gyrus in vivo during dentate spikes and sharp wave bursts. Hippocampus 7: 437-450.

Piatti VC, Davies-Sala MG, Espósito MS, Mongiat LA, Trinchero MF, Schinder AF. 2011. The timing for neuronal maturation in the adult hippocampus is modulated by local network activity. J Neurosci 31: $7715-7728$.

Piatti VC, Ewell LA, Leutgeb JK. 2013. Neurogenesis in the dentate gyrus: Carrying the message or dictating the tone. Front Neurosci 7: 50 .

Pieper AA, Xie S, Capota E, Estill SJ, Zhong J, Long JM, Becker GL, Huntington P, Goldman SE, Shen CH, et al. 2010. Discovery of a proneurogenic, neuroprotective chemical. Cell 142: 39-51.

Pouille F, Scanziani M. 2004. Routing of spike series by dynamic circuits in the hippocampus. Nature 429: 717-723.

Pun RY, Rolle IJ, Lasarge CL, Hosford BE, Rosen JM, Uhl JD, Schmeltzer SN, Faulkner C, Bronson SL, Murphy BL, et al. 2012. Excessive activation of mTOR in postnatally generated granule cells is sufficient to cause epilepsy. Neuron 75: 1022-1034.

Rakic P. 1985. Limits of neurogenesis in primates. Science 227: 10541056.

Ramirez-Amaya V, Balderas I, Sandoval J, Escobar ML, Bermúdez-Rattoni F. 2001. Spatial long-term memory is related to mossy fiber synaptogenesis. J Neurosci 21: 7340-7348.

Ramírez-Amaya V, Vazdarjanova A, Mikhael D, Rosi S, Worley PF, Barnes CA. 2005. Spatial exploration-induced Arc mRNA and protein expression: Evidence for selective, network-specific reactivation. J Neurosci 25: 1761-1768.

Rekart JL, Sandoval CJ, Bermudez-Rattoni F, Routtenberg A. 2007. Remodeling of hippocampal mossy fibers is selectively induced seven days after the acquisition of a spatial but not a cued reference memory task. Learn Mem 14: 416-421.

Revest JM, Dupret D, Koehl M, Funk-Reiter C, Grosjean N, Piazza PV, Abrous DN. 2009. Adult hippocampal neurogenesis is involved in anxiety-related behaviors. Mol Psychiatry 14: 959-967.

Rolls ET. 1996. A theory of hippocampal function in memory. Hippocampus 6: $601-620$.

Rolls ET, Kesner RP. 2006. A computational theory of hippocampal function, and empirical tests of the theory. Prog Neurobiol 79: 1-48.

Rolls ET, Treves A. 1998. Neural Networks and Brain Function. Oxford University Press, Oxford, UK.

Royer S, Sirota A, Patel J, Buzsáki G. 2010. Distinct representations and $\theta$ dynamics in dorsal and ventral hippocampus. J Neurosci 30: $1777-1787$.

Ruediger S, Vittori C, Bednarek E, Genoud C, Strata P, Sacchetti B, Caroni P. 2011. Learning-related feedforward inhibitory connectivity growth required for memory precision. Nature $\mathbf{4 7 3}$ : $514-518$.

Sahay A, Hen R. 2007. Adult hippocampal neurogenesis in depression. Nat Neurosci 10: $1110-1115$.

Sahay A, Wilson DA, Hen R. 2011a. Pattern separation: A common function for new neurons in hippocampus and olfactory bulb. Neuron 70: $582-588$.

Sahay A, Scobie KN, Hill AS, O'Carroll CM, Kheirbek MA, Burghardt NS, Fenton AA, Dranovsky A, Hen R. 2011b. Increasing adult hippocampal neurogenesis is sufficient to improve pattern separation. Nature 472: $466-470$.

Salin PA, Scanziani M, Malenka RC, Nicoll RA. 1996. Distinct short-term plasticity at two excitatory synapses in the hippocampus. Proc Natl Acad Sci 93: 13304-13309.

Sambandan S, Sauer JF, Vida I, Bartos M. 2010. Associative plasticity at excitatory synapses facilitates recruitment of fast-spiking interneurons in the dentate gyrus. J Neurosci 30: 11826-11837.

Santarelli L, Saxe M, Gross C, Surget A, Battaglia F, Dulawa S, Weisstaub N, Lee J, Duman R, Arancio O, et al. 2003. Requirement of hippocampal neurogenesis for the behavioral effects of antidepressants. Science 301: 805-809.

Satvat E, Schmidt B, Argraves M, Marrone DF, Markus EJ. 2011. Changes in task demands alter the pattern of zif268 expression in the dentate gyrus. J Neurosci 31: 7163-7167.

Sauer JF, Strüber M, Bartos M. 2012. Interneurons provide circuitspecific depolarization and hyperpolarization. J Neurosci 32: $4224-4229$.

Saxe MD, Battaglia F, Wang JW, Malleret G, David DJ, Monckton JE, Garcia AD, Sofroniew MV, Kandel ER, et al. 2006. Ablation of hippocampal neurogenesis impairs contextual fear conditioning and synaptic plasticity in the dentate gyrus. Proc Natl Acad Sci 103: 17501-17506.

Saxe MD, Malleret G, Vronskaya S, Mendez I, Garcia AD, Sofroniew MV, Kandel ER, Hen R. 2007. Paradoxical influence of hippocampal neurogenesis on working memory. Proc Natl Acad Sci 104: $4642-4646$

Scharfman HE. 1991. Dentate hilar cells with dendrites in the molecular layer have lower thresholds for synaptic activation by perforant path than granule cells. J Neurosci 11: 1660-1673.

Scharfman HE. 1995. Electrophysiological evidence that dentate hilar mossy cells are excitatory and innervate both granule cells and interneurons. J Neurophysiol 74: 179-194.

Scharfman HE, Goodman JH, Sollas AL. 2000. Granule-like neurons at the hilar/CA3 border after status epilepticus and their synchrony with area CA3 pyramidal cells: Functional implications of seizure-induced neurogenesis. J Neurosci 20: 6144-6158.

Schloesser RJ, Manji HK, Martinowich K. 2009. Suppression of adult neurogenesis leads to an increased hypothalamo-pituitary-adrenal axis response. Neuroreport 20: $553-557$.

Schmidt B, Marrone DF, Markus EJ. 2012. Disambiguating the similar: The dentate gyrus and pattern separation. Behav Brain Res 226: $56-65$.

Schmidt-Hieber C, Jonas P, Bischofberger J. 2004. Enhanced synaptic plasticity in newly generated granule cells of the adult hippocampus. Nature 429: 184-187.

Shors TJ, Miesegaes G, Beylin A, Zhao M, Rydel T, Gould E. 2001. Neurogenesis in the adult is involved in the formation of trace memories. Nature 410: $372-376$.

Sierra A, Encinas JM, Deudero JJ, Chancey JH, Enikolopov G, Overstreet-Wadiche LS, Tsirka SE, Maletic-Savatic M. 2010. Microglia shape adult hippocampal neurogenesis through apoptosis-coupled phagocytosis. Cell Stem Cell 7: 483-495.

Singer BH, Gamelli AE, Fuller CL, Temme SJ, Parent JM, Murphy GG. 2011. Compensatory network changes in the dentate gyrus restore long-term potentiation following ablation of neurogenesis in young-adult mice. Proc Natl Acad Sci 108: 5437-5442. 
Snyder JS, Kee N, Wojtowicz JM. 2001. Effects of adult neurogenesis on synaptic plasticity in the rat dentate gyrus. J Neurophysiol 85: $2423-2431$.

Snyder JS, Choe JS, Clifford MA, Jeurling SI, Hurley P, Brown A, Kamhi JF, Cameron HA. 2009. Adult-born hippocampal neurons are more numerous, faster maturing, and more involved in behavior in rats than in mice. J Neurosci 29: 14484-14495.

Snyder JS, Soumier A, Brewer M, Pickel J, Cameron HA. 2011. Adult hippocampal neurogenesis buffers stress responses and depressive behaviour. Nature 476: 458-461.

Snyder JS, Ferrante SC, Cameron HA. 2012. Late maturation of adult-born neurons in the temporal dentate gyrus. PLoS One 7: e48757.

Spalding KL, Bergmann O, Alkass K, Bernard S, Salehpour M, Huttner HB, Bostrom E, Westerlund I, Vial C, Buchholz BA, et al. 2013. Dynamics of hippocampal neurogenesis in adult humans. Cell 153: 1219-1227.

Spruston N, Johnston D. 1992. Perforated patch-clamp analysis of the passive membrane properties of three classes of hippocampal neurons. $J$ Neurophysiol 67: 508-529.

Spruston N, McBain C. 2007. Structural and functional properties of hippocampal neurons. In The hippocampus book (ed. Andersen P, Morris R, Amaral D, Bliss T, O'Keefe J), pp. 133-202. Oxford University Press, New York.

Staley KJ, Otis TS, Mody I. 1992. Membrane properties of dentate gyrus granule cells: Comparison of sharp microelectrode and whole-cell recordings. J Neurophysiol 67: 1346-1358.

Stone SS, Teixeira CM, Zaslavsky K, Wheeler AL, Martinez-Canabal A, Wang AH, Sakaguchi M, Lozano AM, Frankland PW. 2011. Functional convergence of developmentally and adult-generated granule cells in dentate gyrus circuits supporting hippocampus-dependent memory. Hippocampus 21: 1348-1362.

Surget A, Tanti A, Leonardo ED, Laugeray A, Rainer Q Touma C, Palme R, Griebel G, Ibarguen-Vargas Y, Hen R, et al. 2011. Antidepressants recruit new neurons to improve stress response regulation. Mol Psychiatry 16: 1177-1188.

Sutula T, Cascino G, Cavazos J, Parada I, Ramirez L. 1989. Mossy fiber synaptic reorganization in the epileptic human temporal lobe. Ann Neurol 26: 321-330.

Tashiro A, Sandler VM, Toni N, Zhao C, Gage FH. 2006. NMDA-receptor-mediated, cell-specific integration of new neurons in adult dentate gyrus. Nature 442: 929-933.

Tauck DL, Nadler JV. 1985. Evidence of functional mossy fiber sprouting in hippocampal formation of kainic acid treated rats. J Neurosci 5: 1016-1022.

Tayler KK, Tanaka KZ, Reijmers LG, Wiltgen BJ. 2013. Reactivation of neural ensembles during the retrieval of recent and remote memory. Curr Biol 23: $99-106$.

Toni N, Sultan S. 2011. Synapse formation on adult-born hippocampal neurons. Eur J Neurosci 33: 1062-1068.

Toni N, Teng EM, Bushong EA, Aimone JB, Zhao C, Consiglio A, van Praag H, Martone ME, Ellisman MH, Gage FH. 2007. Synapse formation on neurons born in the adult hippocampus. Nat Neurosci 10: $727-734$

Toni N, Laplagne DA, Zhao C, Lombardi G, Ribak CE, Gage FH, Schinder AF. 2008. Neurons born in the adult dentate gyrus form functional synapses with target cells. Nat Neurosci 11: 901-907.

Treves A, Tashiro A, Witter MP, Moser EI. 2008. What is the mammalian dentate gyrus good for? Neuroscience 154: 1155-1172.
Tronel S, Belnoue L, Grosjean N, Revest JM, Piazza PV, Koehl M, Abrous DN. 2012. Adult-born neurons are necessary for extended contextual discrimination. Hippocampus 22: 292-298.

van Praag H, Kempermann G, Gage FH. 1999. Running increases cell proliferation and neurogenesis in the adult mouse dentate gyrus. Nat Neurosci 2: 266-270.

van Praag H, Kempermann G, Gage FH. 2000. Neural consequences of environmental enrichment. Nat Rev Neurosci 1: 191-198.

van Praag H, Schinder AF, Christie BR, Toni N, Palmer TD, Gage FH. 2002. Functional neurogenesis in the adult hippocampus. Nature 415: $1030-1034$.

Villarreal DM, Do V, Haddad E, Derrick BE. 2002. NMDA receptor antagonists sustain LTP and spatial memory: Active processes mediate LTP decay. Nat Neurosci 1: $48-52$.

Vivar C, Potter MC, Choi J, Lee JY, Stringer TP, Callaway EM, Gage FH, Suh H, van Praag H. 2012. Monosynaptic inputs to new neurons in the dentate gyrus. Nat Commun 3: 1107.

Wang S, Scott BW, Wojtowicz JM. 2000. Heterogenous properties of dentate granule neurons in the adult rat. J Neurobiol 42: 248-257.

Wang JW, David DJ, Monckton JE, Battaglia F, Hen R. 2008. Chronic fluoxetine stimulates maturation and synaptic plasticity of adult-born hippocampal granule cells. J Neurosci 28: 1374-1384.

Wickersham IR, Lyon DC, Barnard RJ, Mori T, Finke S, Conzelmann KK, Young JA, Callaway EM. 2007. Monosynaptic restriction of transsynaptic tracing from single, genetically targeted neurons. Neuron 53: $639-647$

Williams PA, Larimer P, Gao Y, Strowbridge BW. 2007. Semilunar granule cells: Glutamatergic neurons in the rat dentate gyrus with axon collaterals in the inner molecular layer. J Neurosci 27: 13756-13761.

Wiskott L, Rasch MJ, Kempermann G. 2006. A functional hypothesis for adult hippocampal neurogenesis: Avoidance of catastrophic interference in the dentate gyrus. Hippocampus 16: 329-343.

Wojtowicz JM, Askew ML, Winocur G. 2008. The effects of running and of inhibiting adult neurogenesis on learning and memory in rats. Eur J Neurosci 27: 1494-1502.

Xavier GF, Costa VC. 2009. Dentate gyrus and spatial behaviour. Prog Neuropsychopharmacol Biol Psychiatry 33: 762-773.

Yasuda M, Johnson-Venkatesh EM, Zhang H, Parent JM, Sutton MA, Umemori H. 2011. Multiple forms of activity-dependent competition refine hippocampal circuits in vivo. Neuron 70: 1128-1142.

Zhao C, Teng EM, Summers RG Jr, Ming GL, Gage FH. 2006. Distinct morphological stages of dentate granule neuron maturation in the adult mouse hippocampus. J Neurosci 26: 3-11.

Zhao C, Deng W, Gage FH. 2010a. Mechanisms and functional implications of adult neurogenesis. Cell 132: 645-660.

Zhao S, Zhou Y, Gross J, Miao P, Qiu L, Wang D, Chen Q, Feng G. 2010b. Fluorescent labeling of newborn dentate granule cells in GAD67-GFP transgenic mice: A genetic tool for the study of adult neurogenesis. PLoS One 5: e12506.

Zipp F, Nitsch R, Soriano E, Frotscher M. 1989. Entorhinal fibers form synaptic contacts on parvalbumin-immunoreactive neurons in the rat fascia dentata. Brain Res 495: 161-166.

Ziv Y, Burns LD, Cocker ED, Hamel EO, Ghosh KK, Kitch LJ, El Gamal A, Schnitzer MJ. 2013. Long-term dynamics of CA1 hippocampal place codes. Nat Neurosci 16: $264-266$.

Received June 12, 2013; accepted in revised form September 23, 2013. 


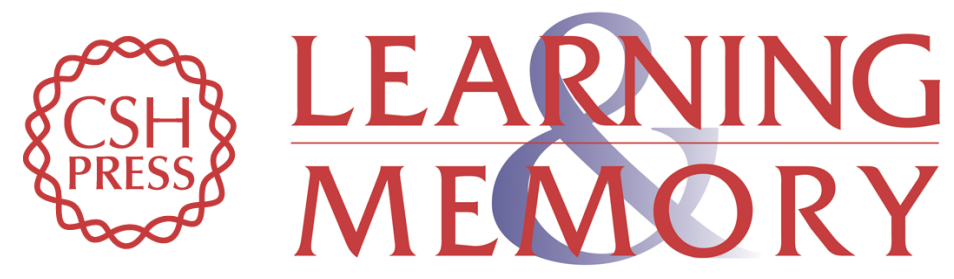

\section{Adult neurogenesis in the mammalian hippocampus: Why the dentate gyrus?}

Liam J. Drew, Stefano Fusi and René Hen

Learn. Mem. 2013, 20:

Access the most recent version at doi:10.1101//m.026542.112

References This article cites 236 articles, 60 of which can be accessed free at: http://learnmem.cshlp.org/content/20/12/710.full.html\#ref-list-1

Creative This article is distributed exclusively by Cold Spring Harbor Laboratory Press for the Commons License first 12 months after the full-issue publication date (see http://learnmem.cshlp.org/site/misc/terms.xhtml). After 12 months, it is available under a Creative Commons License (Attribution-NonCommercial 3.0 Unported), as described at http://creativecommons.org/licenses/by-nc/3.0/.

Email Alerting Receive free email alerts when new articles cite this article - sign up in the box at the Service top right corner of the article or click here. 